\title{
The use of English Determiners in Dialogue Journals by Japanese Second Language Learners
}

\author{
Adriana Rodrigues Bridger
}

Follow this and additional works at: https://researchrepository.wvu.edu/etd

Part of the First and Second Language Acquisition Commons, Language Description and

Documentation Commons, Other Linguistics Commons, and the Reading and Language Commons

\section{Recommended Citation}

Bridger, Adriana Rodrigues, "The use of English Determiners in Dialogue Journals by Japanese Second Language Learners" (2008). Graduate Theses, Dissertations, and Problem Reports. 7989.

https://researchrepository.wvu.edu/etd/7989

This Thesis is protected by copyright and/or related rights. It has been brought to you by the The Research Repository @ WVU with permission from the rights-holder(s). You are free to use this Thesis in any way that is permitted by the copyright and related rights legislation that applies to your use. For other uses you must obtain permission from the rights-holder(s) directly, unless additional rights are indicated by a Creative Commons license in the record and/ or on the work itself. This Thesis has been accepted for inclusion in WVU Graduate Theses, Dissertations, and Problem Reports collection by an authorized administrator of The Research Repository @ WVU. For more information, please contact researchrepository@mail.wvu.edu. 
The use of English Determiners in Dialogue Journals by Japanese Second Language Learners

\title{
Adriana Rodrigues Bridger
}

\author{
Thesis submitted to the \\ Eberly College of Arts and Sciences \\ at West Virginia University \\ in partial fulfillment of the requirements \\ for the degree of
}

\author{
Master of Arts \\ in \\ Foreign Languages
}

\author{
Susan M. Braidi. Ph.D.. Chair \\ Sandra Stjepanovic. Ph.D. \\ Maria Amores. Ph.D.
}

Department of Foreign Languages

Morgantown. West Virginia $200 \mathrm{~s}$

Keywords: English Determiners. Japanese Second Lan guage Learners. Dialogue Journais Copyright 2008 Adriana Rodrigues Bridger 
UMI Number: 1458492

\section{INFORMATION TO USERS}

The quality of this reproduction is dependent upon the quality of the copy submitted. Broken or indistinct print, colored or poor quality illustrations and photographs, print bleed-through, substandard margins, and improper alignment can adversely affect reproduction.

In the unlikely event that the a'sthor did not send a complete manuscript and there are missing pages, these will be noted. Also, if unauthorized copyright material had to be removed, a note will indicate the deletion.

(B)

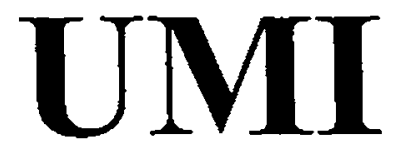

UMI Microform 1458492

Copyright 2008 by ProQuest LLC.

All rights reserved. This microform edition is protected against unauthorized copying under Title 17, United States Code.

ProQuest LLC

789 E. Eisenhower Parkway

PO Box 1346

Ann Arbor, Ml 48106-1346 


\author{
ABSTRACT \\ The Use of English Determiners in Dia logue Journals \\ by J apanese Second Language Learners \\ Adriana Rodrigues Bridger \\ West Virginia University
}

The purpose of this study was to describe the use of English determiners in dialogue journals by $J$ apanese second language learners. The entries of the journals of six Japanese students in an ESL class collected over an eight-week period served as the main source of data for this research project. Three an alyses were performed: the accuracy order of the articles (the a/ an. and 0 ). possessives. and other determiners: the accuracy order of predeterminers. central determiners. and postdeterminers: and an error analysis of the articles $a / a n$. the. and the 0 article. The following major findings emerged: the accuracy order of the English determ iners was from most accurate to the least accurate: 0 .

possessive. other determ iner. the. and $a / a n$ : high percentages of errors of underextension of $a / a n$ and the as well as the low percentages of substitution and overextension errors: and problems with a/an in Type $4[-\mathrm{SR}$. $-\mathrm{HK}]$ and the in Type $2[+\mathrm{SR}$. $+\mathrm{HK}$ ] contexts. These results contribute to research on ESL learners" use of English articles in a naturai written discourse. 


\section{Dedication}

To

Marc. my parents. my sister. and my grandmothers 


\section{Acknowledgments}

First and foremost. I would like to praise God for this amazing victory. Once again the Lord has been faithful and good to me.

Second. I would like to thank my husband Marc for supporting me in everyway throughout this thesis process. Meu amor. your love. prayers. words of encouragement. patience. and protessional computer skills not only have helped me finish this Master's degree. but also they have made me a better person.

I also would like to thank my family in Brazil. My parents. Tiao and Madalena. my sister Fernanda, and my loving grandmothers Biata and Judith. thank you for your prayers and thank you for always encouraging me to pursue my dreams. Also. a special thanks to my in-laws Kay and Ron. Your love and prayers have comforted me during th is thesis project.

I would like to express my sincere gratitude to my committee members. Thank you for investing so much time and work on this thesis project. Dr. Braidi. thank you for your patience, valuable guidance and suggestions, and for never giving up on me. Dr.

Stjepanovic. thanks for your heipful comments and special attention. Thank you Dr. Amores. for your words of encouragement. and precious feedback. I would like my committec members to know that I am very grateful for everything they did for me during this time and for working hard to help me get this done. especially after I moved to Florida.

Finally. I would like to thank the students for participating in this study and for enjoying the dialogue journal process with me. 


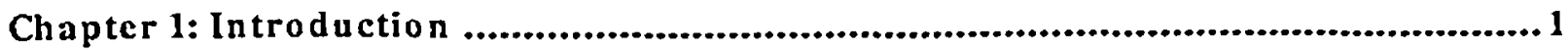

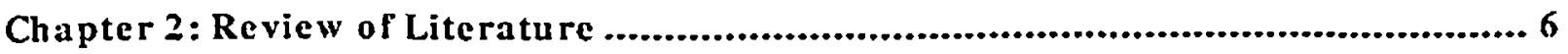

The Articles and Other Determiners in Standard English ...................................................... 7

Acquisition of the English Articles by L2 Learners ...........................................................17

English Article Acquisition by Japanese Students ............................................................... Is

A Brief History of Dialogue J ournals .................................................................................40

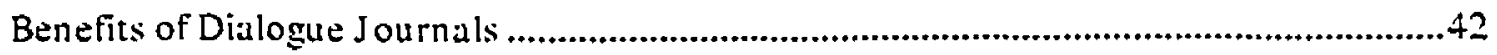

Studies on Dialogue Journals with ESL Students .............................................................43

Chapter 3: Research Design and Methodology .....................................................46

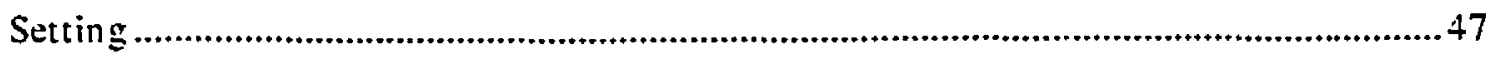

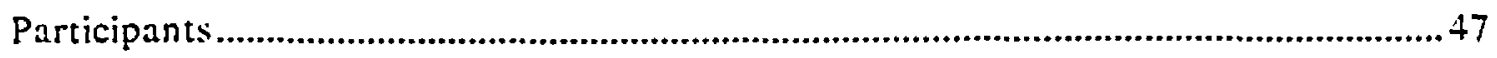

Research Method ...........................................................................................................4

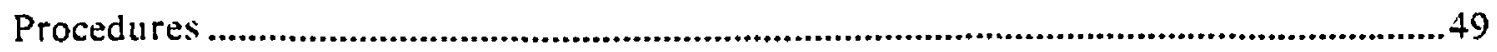

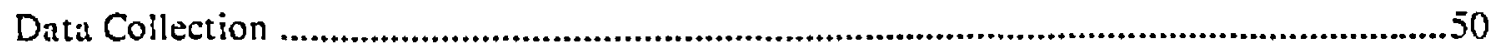

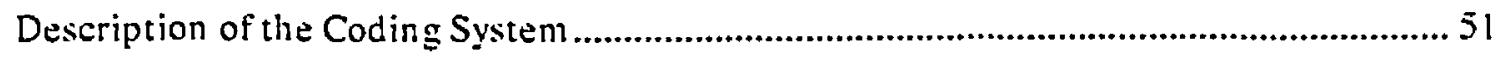

Data Entry and Organization ..........................................................................................54

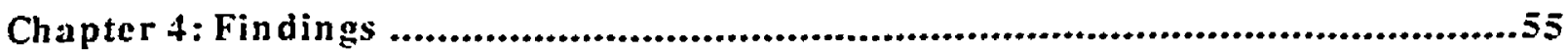

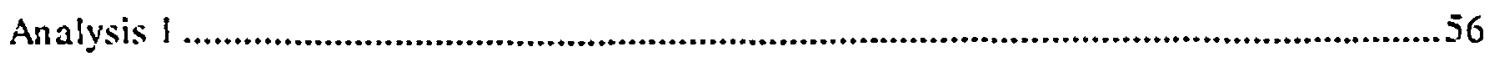

Total number of NP occurrences per student...................................................................56

Types of determ iners used. ............................................................................................

Correctness of the determiners used. ...............................................................................60

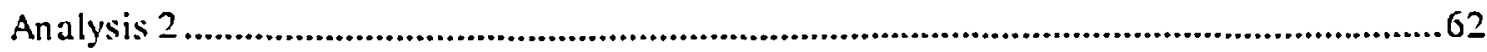

Correctness of predeterm iners. central determiners. and posteterminers used. ........66

Correct individual student usage of the determiners...................................................68 


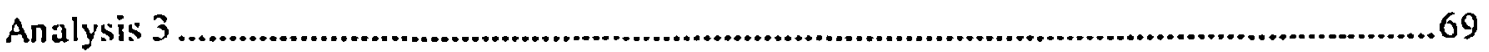

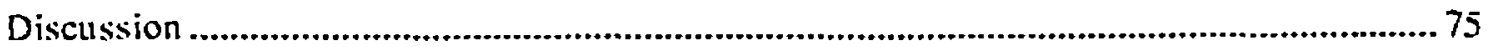

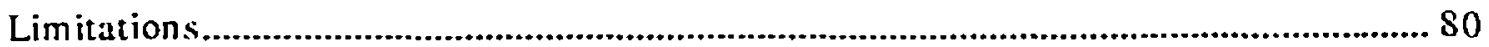

Chapter 5: Conclusion ...........................................................................8 1

Review of the Present Study and Findings ............................................................ \& I

Implications for the ESL Classroom ....................................................................... 2

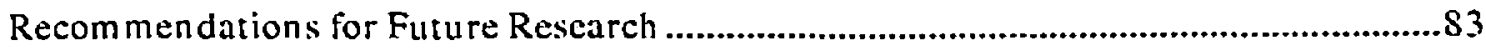

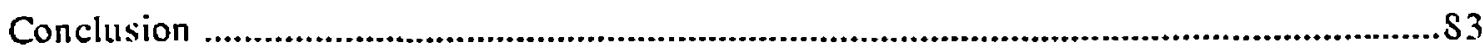




\section{List of Figures}

Figure 4-1: Total Noun Phrases per Student .....................................................................57

Figure 4-2: Noun Phrase Breakdown per Student ................................................................59

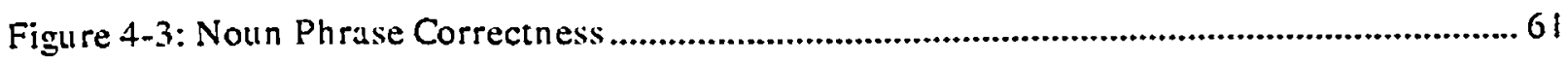

Figure 4-4: Percentage of Correct Determiner Usige ..............................................................62

Figure 4-5: Percentage Correct of Predeterminers. Central Determiners. and Postdeterminers ............67 


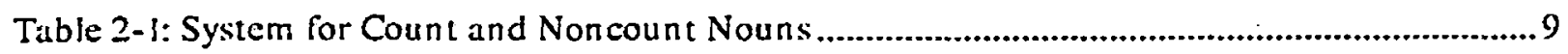

Table 2-2: English Determiners as in Master (1993) ........................................................... 16

Table 2-3: Studies on Article Acquisition by Japanese Students.................................................25

Table 2-4: Studies on the Acquisition of the Articles by L2 Learners Based on Natural Production ....36

Table 3-1: Student In formation - Fina! List of Participants ...................................................4

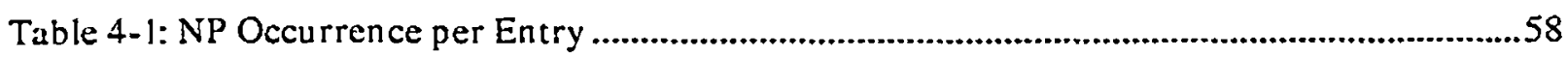

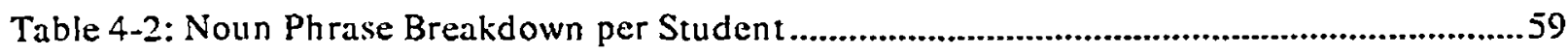

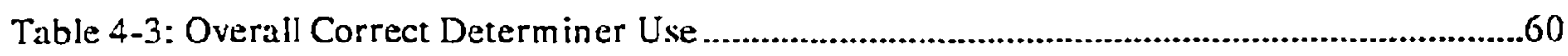

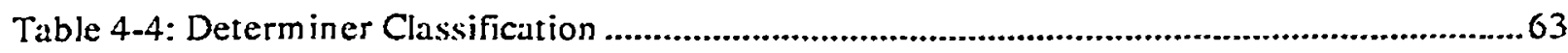

Table 4-5: List of Different Types of Other Determ iners .....................................................64

Table 4-6: Number of Occurrences for Other Determiners ..................................................65

Table 4-7: Number of Occurrences According to English Determiner Classification ..................66

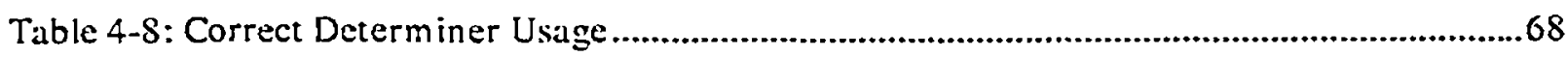

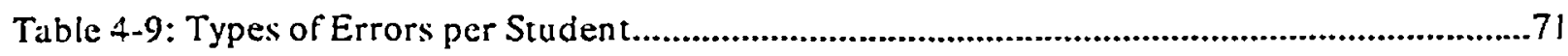

Table 4-10: Distribution of Errors across NP Types ............................................................. 73

Table 4-I1: Number of Occurrences of Underextension Errors across NP Types......................... 73

Table 4-12: Number of Occurrences of Substitution Errors across NP Types ..............................74

Table 4-13: Number of Occurrences of Overextension Errors across NP Types ........................... 75 


\section{Chapter 1}

\section{Introduction}

It is a well known fact that, for many different reasons, second language (L2) learners often have difficulties related to the use of certain grammatical items. Master (1997) states, "What language learners seem to find particularly difficult in acquiring English, generally is grammatical items that are comprised of multiple elements" (p. 220). One such example is the usage of the English articles ( $a / a n$, the, and $\varnothing$ ). The articles belong to a class of grammatical items called determiners (Greenbaum and Quirk, 1990), and the determiners, in general, comprise a grammatical area with $\cdots$ it L2 learners have a lot of problems (Master, 1993).

In the case of the English article system, Master (1997) claims that, in order for L2 learners to select the correct choice of the article, notions such as countability, number, and definiteness must be considered. For that reason, even though the articles are among the smallest and the most common words in English, their usage seems to be very complex (Butler, 2002). In addition, Master (1997) argues that the articles are acquired differently depending on whether or not the learner's first language (LI) contains an article system and that the acquisition of articles is delayed for those learners whose L1 does not contain an article system, such as Japanese.

Several studies have examined the use of the article system by English as a Second Language (ESL) learners from a variety of approaches (e.g., Butler, 2002; Yamada \& Matsuura, 1992); these studies have examined learners' abilities to supply the articles in grammar tests and cloze passages as well as learners" production of the articles in spoken and written discourse. The results of these studies suggest that articles are problem atic for all levels of learners (Yamada \& Matsuura, 1982) and that native language is a factor (Master, 1987). In addition. while teachers of ESL find it difficult to teach the article system 
to their students, the difficulty teachers have in teach ing the article system is even more intensified when they are working with students whose mother tongue does not have an article system [-Art, such as Japanese (Master, 1987). An instructor in the Yam ada and Matsuura study suggested that these students seem to use the English article system almost in a random way, since their use of the system does not resemble the Standard English practice. Also, Thomas (1989, p. 339-340) suggests that a great number of these studies are based on non-naturalistic data obtained from cloze tests. She notes that these types of tests may provide an incomplete perspective of how articles are used by the students. She also points out that only a few studies that are based on natural language data have been conducted (e.g., Huebner, 1983).

One instructional technique which results in natural written production is the dialogue journal. Kreeft (1984) defines dialogue journals as "notebooks in which students and a teacher interact regularly in a written and informal conversation" (p. 47). Many educators of ESL have become familiar with this individualized interactive writing strategy in an attempt to promote natural language production as well as to learn more about the students' interests, backgrounds, and needs. For decades, dialogue journaling has become a very important teaching strategy to support the writing learning process. This support is developed through the very authentic written interaction that is established between the two writers. Personal journals consist of a private "one way" written communication. Dialogue journals, on the other hand, involve partners - usually a teacher and a student, sharing their interests, experiences, needs, and opinions in writing (Hoimes \& Moulton, 1997). The dialogue journal practice allows teachers to interact and get to know students in a very unique way. Furthermore, dialogue journals provide students with the opportunity to learn the forms and syntax of written language through the modeling of a proficient speaker - the teacher. 
One of the first dialogue journal studies carried out with ESL students (Kreeft, Shuy, Staton, Reed \& Morroy, 1984) points out the characteristics that make dialogue journals an effective tool for language acquisition. The results of the study demonstrate that dialogue journals create good conditions for learning such as, exchange of ideas about topics that are relevant to the learning process, emphasis on communication, improvement of reading skills, interaction in a non-threatening environment, and modeling and enhancement of correct grammatical structures. The conditions for learning proposed by Kreeft, et al. (1984) served as the basis for numerous other studies that explored various relevant features related to the use of dialogue journals with ESL learners. However, it appears that very few studies have described the use of second language grammar in the entries of ESL students' dialogue journals.

These findings reflect my own teaching experience with dialogue journals in the ESL classroom. I first became familiar with this strategy while working as a voluntary intern at a public elementary school in the United States. My supervisor at the time used the journals to teach English to international children at this school. The students came from different cultural and language backgrounds and from various different proficiency levels as well. I was fascinated with how well the students responded to the practice, and even when they could not write or speak in English, they would use drawings in their journals until they learned the words to communicate meaning. The journals seemed to promote language acquisition in a natural and friendly environment. I learned to use the students'own experiences and topics they were interested in to teach them the target language. As a result, the children seemed to acquire vocabulary fast, and they were able to use the new acquired words in different contexts. As the years went by, I started to use dialogue journals in my own adult ESL classes. The students seemed to respond very positively to the dialogue journal task proposed to them, and I started to become more in terested in the effectiveness 
of this instructional practice. However, rather than focusing on the broader benefits of dialogue journals, my interest lay more in the effect this practice would have on the students' writing abilities, and more specifically in the students' use and acquisition of certain grammatical items in English within such a discourse context.

From these two different areas of research, the acquisition of English articles and the use of dialogue journals in the language classroom, comes the impctus for the current study. Specifically, the use of English articles by J apanese students of ESL as demonstrated by the entries in their dialogue journals became the focus of this study for two main reasons. First, even though the articles are among the most commonly used words in the English language, it is surprising how complex their usage can be for ESL students (Butler, 2002). The study by Yamada and Matsurura (1982) suggested that the complexity of the English article system can cause many challenges even for advanced students of English. Since the articles are among the most frequent words in the English language, it is understandable that ESL students would like to know how to use them correctly. Therefore, it is important for researchers and instructors to observe and understand how ESL students use English articles in order to help them utilize the system more appropriately. Second, even though several studies have dealt with the description of the use of English articles by ESL students, as Thomas (1989) suggests, a more accurate picture of L2 acquisition of English articles would come from an examination of natural language production such as the written production in dialogue journals, an activity that fosters natural language production in an extended discourse in a non-threatening environment (Kreeft, 1984).

The participants in this current study are all Japanese speakers ([-Art] speakers) enrolled in an ESL class at a small liberal arts college in the United States. This study describes and analyzes the use of the English articles and other determiners by these Japanese students in order to find how these learners use the articles and other 
determiners: specifically the accuracy level of determiner use, the types of errors com mitted by these students as well as the reasons behind such errors.

The present study is organized as follows. In chapter 2 , a review of the literature related to acquisition of the English article system and dialogue journals is presented. In chapter 3, I provide a detailed description of the design and methodology of the study. The results obtained from the data collected from the entries of the Japanese students' dialogue journals are presented and discussed in chapter 4 . Finally, a conclusion is presented in chapter 5 . 


\section{Chapter 2}

Review of Literature

The articles. such as the and $a(n)$. are among the most frequent words used in the English language (Master. 1997: Butler. 2002). However. ESL students have many difficulties learning them (Yamada \& Matsuura. 19\$2). Many ESL instructors may wonder why their students make the decisions they make when it comes to using the English article system. especially in their writings. In fact. as noted earlier. Yamada and Matsuura (1982) reported that an instructor in their study suggested that his students seemed to use the English article system almost in a random way. since it does not seem to resemble the way native speakers use the system.

When it comes to the use of articles. the challenges faced by L2 learners can be seen even in advanced students of English. Master (1997) suggests that not being able to use the article system correctly at a higher level, for instance in academic writings. "may undermine the author's integrity because they (errors) reveal an imperfect control of the language. Imperfect control may, consciously or unconsciously. suggest imperfect knowledge. and if such an attitude is engendered in the mind of a professor grading a student paper, that student"s grade may suffer“"(p. 216).

Master (19S7). as cited by Master (1997). claims that L2 learners whose language does not contain an article system [-Art]. such as Japanese speakers. will take longer to acquire the articles in English than the ones whose language contain an article system [+Art]. e.g.. Spanish speakers. Therefore. some instructors feel it is important to understand how [-Art] learners use articles in English in order to help them apply the system more appropriately. The studies reviewed here obtained results from grammar tests and natural production tasks; however. the results are not conciusive. In an attempt to add to what is 
currently known about article use in natural language production by L2 learners of English. this study describes and analyzes the use of the English article system as well as other determiners in the entries of the dialogue journals of Japanese ESL students. The purpose is to in vestigate the level of accuracy of the English determiners used by these students in natural language production. the types of errors they make and why. To lay a foundation for this study, this literature review is organized as follows: first I provide a definition. explanation. and analysis of the English article system and other determiners in Standard English from various grammarians" perspectives. Second. an analysis of second language acquisition studies of article learning is given. Third. a review of literature on dialogue journals is described. Finally, a discussion of the literature with respect to the proposed study is presented.

The Articles and Other Determ iners in Standard English

As mentioned before. one area in the grammar of the English language that poses many difficulties for ESL students is the articles. According to Greenbaum and Quirk (1990). the English language has three articies: the definite article the. the indefinite article $a(n)$. and the zero $(\emptyset)$ article. They explain that the articles are part of a grammatical group called determiners. The use of the articles in Standard English depends on the noun they accompany. Nouns are placed into different categories: proper. common, count, noncount. concrete. and abstract. The unique reference. which is a characteristic of proper nouns. does not allow determiner and number distinction. Therefore the following examples are grammatically incorrect in Standard English: *the Brazil. *some Philadelphias. Common nouns. on the other hand. allow the occurrence of such a contrast in English: the music. some problems. Count nouns are also known as countable nouns (e.g.. pen/pens). while noncount nouns are also known as mass nous (e.g.. water). Concrete nouns are those that 
can be seen and measured (e.g.. bread. candle). whereas abstract nouns are those that cannot be seen or measured (e.g.. happiness).

Loberger and Welsh (2002) provide a slightly different definition of the different categories of nouns in English. They classify nouns into the following categories: common. proper. abstract. concrete and collective. Loberger and Welsh detine common nouns as the ones "that are the names of things in general" (p. 7). Some examples of com mon nouns are: dog. student. and book. They explain that common nouns are divided into count nouns and mass nouns. Count nouns are those that describe single items that can be counted (e.g.. car. pencil). The determiners used with count nouns can be used in the singular or plural form. according to the number of the given noun (e.g. This car is my favorite: These pencils are blue.). Mass nouns. on the other hand. identify "things not usually considered countable by individual items" (p.S). Some examples of mass nouns are money. milk. and sugar. Loberger and Welsh explain that although mass nouns are considered uncountable. countability of some of these nouns can be obtained when they are used with expressions such as in the following examples: a cup of milk. two spoons of sugar. Proper nouns are the ones that describe particular things associated with an individual name. such as the name of a person. a state. and other things (e.g.. Anna. Florida). Abstract nouns are those "that name a quality. an attribute. an idea. or anything not having physical properties“" (p. 9). Some examples of abstract nouns are kindness. laughter. and sorrow. Concrete nouns are described as the ones that "have physical properties - that is. things that are tangible items" (p.9). Desk. snow, and computer are examples of concrete nouns. A collective noun is a single noun that describes a group of things (e.g.. a flock of birds. family. class). 1

I All the linguistic and sentence examples provided from page 9 through 13 were adapted from Greenbaum and Quirk (990) and Loberger and Welsh (2002). 
According to Green baum and Quirk (1990). in the English language. nouns occur in noun phrases (NP). Master (1993) explains that determiners in English are obligatory items that occur in the beginning of an NP. The type of reference an NP has (i.e.., whether the NP is definite. indefinite. generic, referential or non-referential) is associated with the determiner that co-occurs with it. Greenbaum and Quirk provide a system for count and noncount nouns based on the relationship between definiteness and number. This system is illustrated in Table 2-I below:

Table 2-1

System for Count and Noncount Nouns

\begin{tabular}{llll}
\hline Number & Definiteness & Count & Noncount \\
\hline Singular & Definite & the pen & the water \\
& Indefinite & apen & O water \\
Plural & Definite & the pens & \\
& Indefinite & O pens & \\
\hline
\end{tabular}

Adapted from Greenbaum and Quirk (1990)

Greenbaum and Quirk explain that an NP is characterized as definite by the article the. In other words. the marks an NP "as referring to something which can be identified uniquely in the contextual or general knowledge shared by the speaker and the hearer" (p. 77). The article the can be used with singular and plural count nouns. as well as with noncount nouns.

The boys went out to play.

The President will speuk to the press tomorrow.

The music we heard was beautiful.

He kicked me on the leg.

The indefinite article $a(n)$. however. is used to mark the NPs when a reference cannot be identified by the speaker and the hearer. It is used with singular count nouns.

I bought $a$ car last month. 
Mary saw $a$ squirrel in the park.

He had an apple for lunch.

In general, the $\emptyset$ article has a great correspondence with $a(n)$. since it plays the role of the indefin ite article when used with plural count and noncount nouns.

I like $\emptyset$ sugar in my tea.

$\emptyset$ Whales are interesting animals.

Besides the articles. Green baum and Quirk point out other determiners that co-occur with nouns in NPs. As mentioned before. the type of reference an NP possesses depends on the determiner that accompanies it. They explain that the determiners are divided into three distinct groups based on their placement in the NP in relation to one another. The three groups of determ iners are: predeterm iners. central determ iners. and postdeterm iners.

First of all. predeterminers have to do with quantification and generally precede the central determiners with which they can co-occur in an NP. Greenbaum and Quirk divide this group into two subgroups: (1) all. both. and half and (2) the multipliers (such as. double. and four times).

In an NP, all. both. and half can appear before the articles. the possessives and the demonstratives (e.g.. all the apples, all $m$ y books, all these calls). However. if a determiner itself implies quantification (e.g.. some. each. no. etc.). then all. both and half cannot cooccur with it in an NP (e.g.."all some books. *all no calls). Individually. all is used with plural count nouns and noncount nouns (e.g.. all the students. all students. all the water. all water): both is used with plural count nouns (e.g.. both the cars. both cars): and half is used with singular and plural count nouns. as weli as with noncount nouns (e.g.. half the cake (s). half a cake. half the water: however. *half water is incorrect in Standard English).

Greenbaum and Quirk also note that the multipliers can be used is predeterminers in two ways: 
When the following determiner is the definite article. demonstrative or possessive. the multiplier applies to the noun so determined:

wicel double the length (alength twice as great)

three tim es her salary (a salary three times as large")

When the following determiner is the indefinite article or each or every. the multiplier applies to a measure (such as frequency) set against the unit specified by the following noun:

once a day

twice each game

four tim es every year (Greenbaum \& Quirk. 1990. p. 76).

Central determiners include the articles (the. $a(n)$. and $\emptyset$ ). the demonstratives (this. that, these those), the possessives (my. your, his, her. its.our. their). the wh-determiners (which, whose, whichever, whatever, whosever), the negative determ iner (no), the universai determiners (every. each), the nonassertive dual determiner (either). the negative dual determiner (neither), the general assertive determiner (some), the general nonassertive determiner (any) and the quantitative determiner (enough). Below are examples of central determiners used in Standard English adapted from Greenbaum and Quirk (1990. pp. 7374):

The use of the articles in Standard English has already been previously discussed in this chapter.

I saw a bird in the park.

The bird was yellow and blue.

The demonstratives this and that are used with non count and singular count nouns. while these and those are used with plural count nouns:

She likes this music. but I prefer that music.

This book is mine. but that book over there is Marc's. 
Those cars are better than these cars.

The possessives can be used with singular count. plural count and noncount nouns: I like his car/his kids/his music.

The wh-determiners can be used with singular count. plural count and noncount nouns in the relative. indefinite relative or interrogative forms:

The girl whose vase you broke is here now.

Which books did you like best?

Plealse call me back at 4:00. by which time I shall be home.

The negative determiner can also be used with singular count. plural count and noncount nouns:

They have no house/ no kids/no money.

The universal determiners. the nonassertive dual determiner. and the negative dual determiner can only be used with singular count nouns:

She will talk to every/ each candidate separately.

No parking is allowed on either side of the street.

Parking is allowed on neither side of the street.

The general assertive determiner. the general nonassertive determiner, and the quantitative determiner can only be used with plural count and noncount nouns:

I want some buns/ some bread. please.

They don't have any buns/any bread for dinner.

He has enough materials/ enough paper for the project.

Finally, postdeterminers are placed immediately after determ iners and are divided in to two groups: ordinals (e.g.. first. last) and quantifiers (e.g... Wo. a lot of. many). Whenever ordinals and quantifiers can occur in the same NP. ordinals are placed before quantifiers:

The first wo sentences in this paragraph are beautiful.

His last few words were very rude. 
His other many talents include painting and acting.

Greenbaun and Quirk (1990) explain that the quantifiers few and little have some differences worth mentioning: few can only occur with plural count nouns, while little occurs with noncount nouns: when little and few follow the indefinite article $a$. they acquire a positive meaning. when $a$ is not present in the NP. lintle and few have a negative meaning:

We read a few books th is weekend. (i.e.. several)

We read few books this weekend. (i.e., hardly any)

He drank a little juice in the morning. (i.e., some)

He drank little juice in the morning. (i.e.. hardly any)

The classifications and definitions of the usage of the determiners in English proposed by Greenbaum and Quirk (1990) and Loberger and Welsh (2002) presented above are very important for this current study because they serve as basis for the analysis of the use of the determiners by the Japanese ESL students.

It is also important to state that the articles as well as the other determiners have been analyzed in different ways through the years. The studies presented below also provide essential information for this current study. According to Huebner (1983). the articles in English basically describe noun phrase referentiality. He suggests that the obligatory. optional. and ungrammatical classifications used in previous studies were not refined enough to analyze article usage. He explains that noun phrase reference is described "in terms of two binary features [+/ In formation Assumed Known to the Hearerl $([+/-\mathrm{HK}])$ and $[+/-$ Specific Referent $]$ ([+/-SRI)“"(p. 132). The two binary features bring about four noun phrase contexts of article use in Standard English. In his study Huebner (1983) uses the following four noun phrase contexts, which he based on Bickerton (19S1). The examples below are adapted from Butler (2002, pp. $478-479)$ and Thomas (1989. p. 337):

I- Generics: [-Specific Referent! , [+Assumed Known to the Hearer] Noun Phrases (NP) that fall in this category can be marked with the $a(n)$. or $\emptyset$. 
D Flowers bloom in the garden.

The Japanese is an in teresting people.

An apple a day keeps the doctor away.

2- Referential Definites: [+Specific Referent] , 1+Assumed Known to the Hearer] These are NPs marked with the.

The Queen of England is very kind. (unique referent)

Please tell the woman to stand next to the little girl. (when the referents are physically present)

I saw a dog at the park. The dog barked at me. (previously mentioned referents)

She walked to his door and rang the bell. (assumed known referents)

3- Referential Indefinites: [+Specific Referent] , [- Assumed Known to the Hearer] This category includes NPs marked with $a(n)$ or $\emptyset$.

I saw a little boy in the store. (first mention NP. assumed not known by the hearer) He keeps sending $\emptyset$ flowers to her.

4- Nonreferentials: |-Specilic Referent [. [-Assumed Known to the Hearer] NPs in this category are marked with $a(n)$ or $\emptyset$.

Paul is an engineer.

He did not use a pen to sign the document. (NP in the negation scope)

Do you have apen? (NP in the question scope)

I'd like to buy a car. (NP in irrealis mode)

Q Scientists should come up with the cure for AIDS.

In later studies (Thomas 1989 and Butler 2002), a fifth category that includes idiomatic expressions (formulaic use) was added to Huebner's NP context of article use:

5- Idiomatic Expressions

The NPs in this category can be marked with $a(n)$. the or $\emptyset$.

All ol a sudden, she opened her bedroom door. In the 1950\%, Rio de I aneiro was the capital of Brazil.

Mary said the test was difficult. but I thought it was a piece of $\emptyset$ cake.

Master (1993). just like Greenbaum and Quirk (1990). assumes that the articles belong to a class of grammatical items called determiners. According to Master. there are two obligatory elements in the composition of a noun phrase (NP): the noun itself and a determiner. He explains that a noun cannot occur alone in an English sentence. It must 
have a determiner preceding it.= Therefore, every noun requires a determiner in English, and for that reason, determiners are words that occur constantly in this language. In his study, Master, just like Greenbaum and Quirk (1990), claims that due to co-occurrence restrictions. the determ iners are placed into three different groups: predeterminers, central determiners, and postdeterminers. He explains that eentral determiners are the most important ones since they form the largest group of determiners; the formation of an $\mathrm{NP}$ requires at least one central determiner; and only one central determiner can be present in an NP at a time (i.e.. they are mutually exclusive). Master adds that predeterminers and postdeterminers "... are not obligatory and are not mutually exclusive with the articles" ( $p$. 3). Table 2-2 displays the three groups of determiners as indicated in Master (1993).

Table 2-2

English Determ iners as in Master (1993)

\begin{tabular}{|c|c|c|}
\hline Predeterminers & Central Determiners & Postdeterminers \\
\hline Quantifiers (e.g., $a l l)$ & Articles $(a / a n$, the,$\emptyset)$ & $\begin{array}{l}\text { Cardinal Numerals (e.g., } \\
\text { two) }\end{array}$ \\
\hline $\begin{array}{l}\text { Multipliers (e.g.. both, twice. } \\
\text { double) }\end{array}$ & Demonstratives (e.g.. this) & $\begin{array}{l}\text { Ordinal Numerals (c.g., } \\
\text { second) }\end{array}$ \\
\hline $\begin{array}{l}\text { Fractions (e.s.. half. one- } \\
\text { third) }\end{array}$ & Possessives (e.g.. my.John's) & $\begin{array}{l}\text { General Ordinals (e.g., } \\
\text { next) }\end{array}$ \\
\hline \multirow[t]{6}{*}{$\begin{array}{l}\text { Intensifiers (c.g.. what. } \\
\text { such) }\end{array}$} & $\begin{array}{l}\text { Assertive/ Non assertive (e.g.. } \\
\text { some) }\end{array}$ & $\begin{array}{l}\text { Quantifiers (e.g., many, } \\
\text { few, several, litle) }\end{array}$ \\
\hline & Negative (e.g., no) & \\
\hline & Universal (e.g., each) & \\
\hline & $\begin{array}{l}\text { Nonassertive Dual (e.g., } \\
\text { either) }\end{array}$ & \\
\hline & Negative Dual (e.g., neither) & \\
\hline & Wh-determiners (e.g.. which) & \\
\hline
\end{tabular}

2 It is important to state that in sentences such as "Whales are interesting animals": the $\emptyset$ determiner precedes the noun whales in the NP. 
Master (1993) and Greenbaum and Quirk (1990) present the same main classifications for the determiners in English: predeterminer, central determiner, and postdeterminer. However, when they place these determiners in to their subcategories, some differences in the two classification systems are noticed. Master describes four subgroups of predeterminers and postdeterminers, while Greenbaum and Quirk only depict two.

Greenbaum and Quirk add the subgroup quantitative determiner to the central determiner category. These differences will be explained further in Chapter 4 , when the analyses and results of this current study are discussed. It is important to state that understanding Master's and Greenbaum and Quirk's classification systems of the English determiners is essential, since they will be the foundation for one of the analyses of the determiners used by the $J$ apanese ESL students in this current study. Acquisition of the English Articles by L2 Learners

The analyses presented above confirm that the determiner system in English is quite complex. This complexity is even more evident when considering how the system is used by L2 learners of English. Several studies regarding the acquisition of the English articles by L2 learners have been conducted. Some of these studies are reviewed below.

As mentioned earlier, the articles are among the smallest and most frequent words used in Standard English. The use of the English articles, however, poses a number of challenges for English learners (Yamada \& Matsuura, 1982). Master (1997) explained that errors associated with article use do not lead to miscomprehension, and for that reason ESL studen ts may believe they have already learned the complex system, when most of the time they have not. Master suggested that when these students are required to compose at the academic level, however, article errors may indicate poor language control, which may result in a lower grade. Even though many educators do understand the importance of helping their students learn the article system. they are faced with the everyday challen ges 
of the task. Master (1987), as cited by Master (1997), claimed that the manner in which the English articles are acquired depends on whether or not an article system is present in the learner's first language. His study revealed that [-Art] speakers, such as J apan ese speakers, are approximately one level of acquisition bchind when compared with [+ Art] speakers, e.g. Spanish speakers. Master concluded that $F$-Art / speakers will eventually acquire the article system, but it will take longer for them to do so than [+Art] speakers. Since the present study focuses on the use of the En glish articles as well as other determiners by Japanese learners, a closer examination of the literature in this specific area is warranted.

\section{English Article Acquisition by Japanese Students}

As just noted, the Japanese language does not contain an article system (Takahashi, 1997; Yamada \& Matsuura, 1982; Butler. 2002 and Master, 1997). Yamada and Matsuura (1982) claimed that the difficulty Japanese students have in using the English articles is attributed to two factors: "the absence of an article system in Japanese and the complexity of the English article system, which is specified in terms of three semantic notions not explicitly expressed in Japanese: specific/ nonspecific, countable/uncountable, and singular/plural with respect to the nouns [noun phrases! co-occurring with given articles" (p. 50). Although several studies have been conducted on the acquisition of the English article system, Takahushi (1997) suggested that there is still much to be investigated in this area in order to resolve the issues pertaining to the difficulties faced by $J$ apanese as well as other ESL learners when using the English articie system. In order to understand the chalfenges faced by [-Art] speakers in L2 acquisition, a review of literature on English article acquisition by native speakers of $J$ apanese $([-$ Art $])$ is presented below.

Yamada and Matsuura (1982) examined the use of the English articles among 70 Japanese students of English as a Foreign Language (EFL). The students were placed in to two groups. Group 1 consisted of 35 in termediate level students, and Group 2 comprised 35 
advanced level students of English. All of their subjects had formal English instruction. and none of them had ever traveled to an English-speaking country. In order to assess the subjects' knowledge of the English articles, Yamada and Matsuura used a cloze-type test. The same cloze test was given twice to the students in a classroom situation with a week interval between the two test sessions. This was done in an attempt to test the stability of the answers given by the Japanese students. When the responses were the same in the two test sessions, they were considered stable. Different responses for the same items in the cloze test were considered unstable. The responses marked Stable-Correct (S-C) meant that the students had 'acquired' the articles, and the responses marked Stable-Incorrect (S-I) meant that the stucient had fossilized the wrong answers.

In addition to the two test sessions, a question naire was also given to the students. The researchers wanted to find out how many of the responses that the students had given in the first test they actually remembered. Sixty percent of Group 1 and sixty-three percent of Group 2 reported that they remembered less than forty percent of their responses, while only fourteen and sixteen percent of Group 1 and Group 2 participants declared they remembered more than sixty percent of their responses. Based on this result, the researchers concluded that the effects of the first test responses on the second ones were not relevant.

The level of difficulty ${ }^{3}$ for the, $a(n)$. and $\emptyset$ combined (based on the S-C responses analyzed) was approximately seventy percent even for the advanced group. The analysis of

${ }^{3}$ While Yamada and Matsuura described these results as representing an order of "difficulty," earlier work in L2 morpheme acquisition studies distinguished between three types of order: accuracy, acquisition, and difficulty. Hatch (1978) provided a definition for the term "accuracy order". She stated that: 
the types of S-I responses indicated that the most occurring type of incorrect responses was the use of the instead of $\emptyset$; followed by the use of the instead of $a / a n$ among the two groups. Yamada and Matsuura named this strategy overspecification. They explained that this strategy should not be considered completely wrong “because even a competent speaker of English may overspecify certain nouns by intentionally visualizing the situation in the text, or by presupposing that both the writer and the reader already know the nouns referred to in the text" (p. 59). Contrarily, the underspecification types of incorrect responses (the use of $a / a n$ instead of the, and the use of $\emptyset$ instead of the) were infrequent. The general order of difficulty from the easiest to the most difficult was: (1) the, (2) $a(n),(3) \emptyset$ for Group 1 intermediate students and (1) the, (2) $\emptyset,(3) a(n)$ for the Group 2 advanced students. Yamadia and Matsuura explained that there is a possibility that the high accuracy level of the definite article was caused partially by the overspecification strategy. The results of the analysis of the articles in the Yamada and Matsuura study provide suggestive in formation for this current study regarding the level of articles accuracy.

In another study by Takahashi (1997), two hypotheses were examined: if the presence of a modifier after a head noun would make Japanese learners of EFL choose the even if the referent is not unique in the situation relevant to the speaker and the hearer; and if the article selection in formulaic language (e.g., Where's the $X$ ?, the first $X$ ) is more

I have chosen to use the term "accuracy order" as I feel it is a more precise description of what morpheme studies reveal than the terms previously employed. i.e.. "acquisition order" (Dulay and Burt) and "difficulty order" (Baley. Madden and Krashen). What we are measuring in a cross-sectional study is the percentage of times a subject accurately supplies a morpheme form in an obligatory context (p. 379).

In the current study. I will refer to levels of "accuracy" instead of "difficulty." 
accurate than in rule-governed language use. Ninety-nine Japanese EFL college students were the participants in the study. A multiple choice cloze test and a multiple choice article insertion test were given to the participants. The researcher regarded the top 30 participants in the cloze test as high English proficiency learners and the bottom 30 as low English proficiency learners. In the article insertion test. the subjects were to complete the senten ces by circling either the, $a(n)$, or X (when neither the first two options were necessary). The results showed that the participants answers were more accurate when the was required by noun phrases modified by a prepositional phrase or a relative clause than when it was not. In general, the students tended to use the before modified NPs regardless of whether or not the referent was unique in the situation. Thus. Takahashi suggested that learners "may benefit from being explicitly taught that the can not be used when the referent is not unique in the situation relevant to the speaker and the hearer" (p. 104). In addition. the results revealed that the students were more accurate when using the in formulaic language (common use) than in rule-governed language (non-common use). Takahashi. however, suggested that the native speaker's competence includes not only the ability to rely on memorized expressions. but also the ability to make the right choices regarding the use of the articles. whether or not the NP contains a commonly used expression. Therefore, he proposed that $J$ apanese students should be taught the situations in which the can occur.

In another study. Yoon (1993) explored the perceptions of noun countability by both native speakers of English and J apanese students of ESL in order to address the difficulty of article acquisition. Twenty-seven Japanese graduate students at three different American institutions of higher education and 31 native speakers of English in the ESL teacher training program of an American college served as subjects for the study. Two essay-texts written by native English speakers were used. A two-part test was given to the subjects. For the first part of the test, both the native English speakers and the Japanese students had to 
determine whether a list of $\$ 7$ nouns taken out from the essay-texts were countable or uncountable. without a given context. The objective of this task was to determine whether or not the native speakers and the Japanese students had the same perceptions regarding the countability of the given English nouns. For the second part of the test. the researcher extracted all in stances of the $a(n)$. and $\emptyset$ from the original essay-texts. and the participants were asked to fill in the blanks with the appropriate article. This task was devised to determine how much influence the subjects" previous decisions on countability had in their article choices in the given essay situations. Even though the subjects were asked to fill in the blanks of the essay-text with the. $a(n)$. and $\emptyset$. for the purpose of the study. only instances of obligatory $a(n)$ were analyzed.

The results of the first part of the test showed that speakers of the same language may perceive nouns differently when it comes to countability. that both the native speakers and the non-native speakers had a greater perception of countability of nouns rather than non-countability. and that there were certain types of nouns that were considered countable by native speakers. but were judged as uncountable by the Japanese students and vice-versa (e.g.. assortment was considered countable by the native speakers and uncountable by the non-native speakers: end was considered uncountable by the native speakers and countable by the non-native speakers).

The second part of the test revealed that the Japanese students had an overall low percentage of use of $a(n)$ in obligatory contexts. and that there is a possible connection between the indefinite article $a(n)$ supplied by the Japanese participants in the cloze test and their previous choices of countability of a given noun. Yoon conciuded that whenever the students considered the noun to be countable. a/ an was used in context. and when they considered the noun to be uncountable. $\emptyset$ was used. She argued that "it is the in itial noncountability intuitive judgment which took precedent over meaning in context“ (p. 283). In 
addition. she explained that if noun countabillity is determined according to the context. then the context must be considered. Yoon also indicated that Japanese students have problems understanding how native speakers of English use context to select the right article. for example. the difference between "My sister had _ great beauty in her youth. and My sister was _ beauty in her youth" (p. 2S4). She suggested that noun countability presentations in grammar books should be viewed carefuily.

Butler (2002) examined the kinds of metalinguistic knowledge employed by L2 learners in selecting the English articles. Her subjects were $S O$ J apanese learners of English and 20 native Engiish speakers serving as the control group. The $80 \mathrm{~J}$ apanese students were placed into four different groups based on their English language proficiency. Her method consisted of three tasks: a questionnaire with questions about her subjects ${ }^{*}$ English language education. in fill-in-the-article test (cloze test). and an interview.

Once the students completed the fill-in-the-article test. they were asked to provide the researcher with the reasons for their article choices. As Butler expected. the fill-in-thearticle test revealed that the more proficient the participants were. the more accurate their article choices. In her analysis of the reasons for article choice. Butler noted that the higher proficiency students demonstrated more specific reasons for their article choices than did the lower proficiency students. In addition, the number of instances in which the students from both groups did not express any explanation for their choices was low. indicating that the J apanese students were in part able to express their metalinguistic knowledge.

She also observed that the highest percentages of errors were caused by referentiality problems. These problems were subcategorized into two groups: (1) misdetection of referentiality (when the learners were not able to identify at least one of the referentiality features. SR and HK): and (2) when students were not able to indentify referentiality altogether. Referentiality detection and misdetection of noun coun tability were considered 
great problems for both groups. and they prevented the students from selecting the articles correctly. She observed a greater number of problems with the $[+/-S R]$ feature with the lower proficient groups than with the advanced group of students. However. she found that problems with the $[+/-\mathrm{HK}$ ] feature remained an issue for both the lower and the higher proficient groups. The data gathered from the interview showed that depending on their level of proficiency. the students employed different hypotheses to use the article system. For example. the context-insensitivity hypothesis was noticed in low proficient students: the hypothesis that shows sensitivity to the wrong contexts was noticed in students with lower to mid level proficiency: and the hypothesis that shows sensitivity to a range of relevant contexts was noticed in high proficient learners. Butler used Huebners four NP environments for article use. but. as did Thomas (19S9). added a fitth type for idiomatic expressions and conventional uses in her classification system. This is relevant because the results of the Takahashi (1997) study showed that the participants" use of the articles wals more accurate in formulaic language (common language use) than in non-common language use. The analysis of the accuracy of the use of idiomatic expressions is important. and it seems appropriate for this current study since it comprises common language use (e.g.. in the 1970 s. all of a sudden) that students may be more familiar with. and therefore more inclined to use accurately in their writings.

The studies on article acquisition by Japanese students mentioned above (Butler. 2002: Yamada \& Matsuura. 1982: Takahashi. 1997: and Yoon. 1993) were conducted in an attempt to understand and clarify some of the many difficulties Japanese students have when using the English article system. Table 2-3 displays a summary of the studies on article acquisition by J apanese students described above. All of these studies were based on data collected from cloze tests. in which the subjects are required to fill in the blanks with articles into a written text. 
Table 2-3

Studies on Article Acquisition by Japanese Students

\begin{tabular}{|c|c|c|c|}
\hline Study & Articles examined & Tasks & Results \\
\hline $\begin{array}{l}\text { Yamada and } \\
\text { Matsuura (1982) }\end{array}$ & $\begin{array}{l}\text {-the. } a(n) \text { and } 0 \\
\text {-accuracy level } \\
\text {-difficulty order of } \\
\text { article acquisition }\end{array}$ & $\begin{array}{l}\text {-cloze test } \\
\text {-repeat cloze test } \\
\text {-questionnaire } \\
\text {-2 different } \\
\text { proficiency groups }\end{array}$ & $\begin{array}{l}\text {-accuracy level of } \\
\text { the. a(n). and } \emptyset \\
\text { around } 70 \% \\
\text {-difficulty order from } \\
\text { the easiest to the } \\
\text { most difficult: (1) } \\
\text { the.(2) a(n). (3) } \emptyset \text { for } \\
\text { intermediate group } \\
\text { and (1) the.(2) } \emptyset \text {. (3) } \\
\text { a(n) for advanced } \\
\text { group }\end{array}$ \\
\hline Yoon (1993) & $\begin{array}{l}\text {-perceptions of } \\
\text { countability and } \\
\text { non-countability } \\
\text { affecting article } \\
\text { choice }\end{array}$ & $\begin{array}{l}\text {-2 part-test: noun } \\
\text { countability without } \\
\text { context and cloze test }\end{array}$ & $\begin{array}{l}\text { - same language } \\
\text { speakers perceive } \\
\text { countability } \\
\text { differently } \\
\text {-reversed } \\
\text { countability } \\
\text { perception between } \\
\text { Li and L2 speakers } \\
\text {-low \% of use of } a(n) \\
\text { in obligatory } \\
\text { contexts by J apanese } \\
\text {-correlation between } \\
\text { the use of } a(n) \text { in the } \\
\text { cloze tests and } \\
\text { previous noun } \\
\text { countability } \\
\text { selections }\end{array}$ \\
\hline Takahashi (1997) & $\begin{array}{l}\text {-selection of the } \\
\text { influenced by the } \\
\text { presence of modifier }\end{array}$ & $\begin{array}{l}\text {-cloze test } \\
\text {-multiple choice } \\
\text { article insertion test }\end{array}$ & $\begin{array}{l}\text {-answers more } \\
\text { accurate when NP } \\
\text { modified by a } \\
\text { relative clause } \\
\text { required the than } \\
\text { when it required } a(n) \\
\text {-the more accurate } \\
\text { in frequently used } \\
\text { sentences }\end{array}$ \\
\hline
\end{tabular}




\begin{tabular}{|c|c|c|c|}
\hline Study & Articles exim ined & Tusks & Results \\
\hline Butler (2002) & $\begin{array}{l}\text {-metalinguistic } \\
\text { knowledge of L2 } \\
\text { learners for article } \\
\text { use } \\
\text {-L2 learners } \\
\text { understanding of } \\
\text { [+/-SR]. [+/-HK]. } \\
\text { countability } \\
\text { - differences in } \\
\text { learners" } \\
\text { metalinguistic } \\
\text { knowledge of article } \\
\text { choice }\end{array}$ & $\begin{array}{l}\text {-questionnaire } \\
\text {-close test } \\
\text { - interview }\end{array}$ & $\begin{array}{l}\text {-the more proficient } \\
\text { the participants. the } \\
\text { more accurate article } \\
\text { choices. } \\
\text {-lower proficiency } \\
\text { students have more } \\
\text { problems with the } \\
\text { [+/-SR] } \\
\text {-problems with I+/- } \\
\text { HK] found amonga!l } \\
\text { groups of Japanese } \\
\text { students. } \\
\text {-different learner } \\
\text { hypotheses are used } \\
\text { to comprehend the } \\
\text { English article } \\
\text { system. }\end{array}$ \\
\hline
\end{tabular}

Thomas (1989). however. claimed that "there are pitfalls inherent to the interpretation of cloze tests. and. in any case. data gathered in this way give an inadequate view of how learners actually use articles" (p. 339). Therefore. it is necessary to exam ine the acquisition of article usage in other types of tasks.

Tarone (1985) and Tarone and Parrish (1988) analyzed the accuracy of second language learners" production of the English articles when asked to perform different tasks. Tarone (1985). as cited in Tarone and Parrish (1988). found that the accuracy with which the articles were used varied depending on the task performed. She also reported that the changes in accuracy of article use were very significant. Tarone. however. was not able to determine the actual causes of this variability in this study. Tarone and Parrish (1988) performed a more refined analysis of the Tarone (1985) data. which emphasized the function of the articles and the distribution of the NP Types proposed by Huebner (19S3) according to the different tasks proposed. The researchers were concerned with whether or 
not a specific task would favor the use of a particular NP type. The three tasks performed by the students were (1) a grammar test. (2) an oral interview, and (3) an oral narration task. The results indicated that the number of instances of Types $2([+S R],[+H K])$ and $3(1+S R]$. [-HK]) of Huebner's NP category in the grammar test were smal] in comparison with the interview and the narrative tasks. In addition. these NP types in the grammar test were provided by the researcher and not by the learners. In both the oral interview and the oral narration task, the most frequently elicited NP Type was Type $2(|+S R|$. [+HK|). Type 3 $([+\mathrm{SR}] .[-\mathrm{HK} \mid)$ was elicited at a similar percentage in the oral tasks. However. Tarone and Parrish found that the two production tasks did elicit different amount of NP Types. Types 1 $([-S R .+H K \mid) .2([+S R \mid .[+H K])$, and $4([-S R||-.H K])$ were produced at very different rates between the oral tasks. Tarone and Parrish concluded that the pattern of accuracy in article use varied with task and NP type. Furthermore. their analysis showed that accuracy on the grammar test was by far the lowest when compared with the interview and narrative tasks and that the measures used in Tarone (1985) showed that this difference was highly significant statistically. Therefore. the researchers found that the natural production tasks (interviews and oral narration) generated a lower number of errors when compared with the cloze test. They attributed the higher accuracy of the articles in the production tasks to the general influence of communicative pressure. In other words, Tarone and Parrish suggested that in order for the speaker (in the narrative task) to convey the message effectively, he or she must use certain types of NP correctly, so that the listener can follow the events and the referents used in the story. and this was reflected in higher accuracy for the narrative task (90\%) than for the interview (82.6\%). In addition to that. Tarone and Parrish explained that since production type taskis elicit more cohesive discourse, in the Tarone (1985) study. the use of some grammatical items. such as the articles. tended to become more accurate as the task progressed. 
In another study. Mizuno (1985), the development of the interlanguage process in $\mathrm{J}$ apanese students of English in acquisition-poor en vironments (i.e.. in an EFL classroom setting) is analyzed. First. Mizuno performed a preliminary study in which he asked 100 English students and teachers in Japan questions based on their knowledge of the use of the articles. He found that both the students and the teachers had limited knowledge of the use of the and $a(n)$, that they did not understand the principle of the use of $\emptyset$. and that they had problems differentiating the use of the $a(n)$-form from the the-form. He explained that his subjects had noexperience living in an English-speaking country and that all of them had taken English lessons in Japan for a few years. Later, based on the results of the preliminary study. Mizuno decided to in vestigate how the interlanguage is developed in $J$ apanese English as Foreign Language (EFL) learners in such acquisition -poor environments.

The subjects were $353 \mathrm{~J}$ apanese students who were placed into nine different groups depending on their English proficiency level. The study was designed to find what types of errors Japanese EFL learners commit while acquiring the English articles, when the appearance and disappearance of these errors occur in the students interlanguage. and why these errors occur in Japanese EFL students in acquisition-poor environments. The students were given an error-correction test, a word arrangement test. and a multiple choice cloze test. In addition to the objective tests. Mizuno used a twenty-minute English essay test as a productive test to enhance the validity and reliability of the tests employed in his study. He stated that "it fthe essay test | required the learner not merely to use the language in the normal contextual sequences, but also to relate extralinguistic context to sequences of elements in English" (p. 16). The results from the objective tests showed that Japanese adult EFL learners make five distinct types of errors when using the English article system. Word order. in which the order of the articles and the adjectives that follow them are inverted 
(e.g., *Th is is new a car.) and co-occurrence, in which the articles and other determiners are juxtaposed (e.g.." A this pencil is on the floor.) are types produced at elementary stages. The errors that keep occurring in the interlanguage process are underextension. in which the articles are omitted (e.g.. "They are $\emptyset$ parents of this little girl.). overextension. in which a/ an or the are used instëad of $\emptyset$ (e.g.." after the dinner. "a bealutiful houses) and substitution. in which the is used instead of $a / a n$ or vice versa (e.g." a best student). The data obtained from the productive test (essiy test) confirmed the results of the objective tests except for the fact that errors of underextension were more evident in the data collected from the essay tests; whereas errors of overextension were more evident in the data collected from objective tests.

Mizuno concluded that "the contrasting results of the judgmental and productive tests offer us important insight into the interlanguage strategies of the learner. but they may also be related to the differences in the conditions imposed on the subjects by the distinct nature of the two types of test" (p.21). In addition, he suggested that in linguistic activities (e.g.. essay writing) students tend to focus on what they are trying to express and for that reason, they seem to monitor the use of the articles less, as opposed to the situation observed in objective tests (grammar tests). These tindings differ from the ones obtained in the Tarone and Parrish (1988) study. in which they suggested that the use of the articles was more accurate as the students" natural production task became more cohesive.

In addition to studies with explicit article elicitation. there have been other studies on the acquisition of English articles by L2 learners based on natural language production. For example. Huebner (1983) described a longitudinal study of a young adult Hmong and Lao speaker acquiring English in a natural setting without formal instruction. Huebner analyzed seventeen one-hour tapes collected every three weeks over a period of one year. In his subject's speech. the article the was pronounced da. Therefore. Huebner refers to the as 
da throughout his book. For the analysis of the article $d a$, nine tapes were exam ined. He classificd all noun phrases according to the NP context of article use previously described in this chapter. The results showed that at first the participant overused and overgeneralized da with all nouns, which Huebner called the-flooding. A decrease in the amount of da flooding was later on noticed in [-SR. $-H K$ / cases and gradually the participant was able to use $d a$ with $[+\mathrm{SR},+\mathrm{HK}]$ and $[-\mathrm{SR} .+\mathrm{HK}]$ cases almost exclusively. These findings supported Huebner's claim that his subject might at first relate the use of $d a$ with the $[+\mathrm{HK}]$ feature. For the purpose of his study. Huebner elim inated certain cases from his analysis such as proper nouns, reformulations, repetitions. idioms. and everyday expressions (e.g., "eat dinner", "in the morning", etc.). Also elimin ated from the analysis were possessives (e.g." "my brother") and second subsequent noun phrases in a series (e.g.. "the man and the women"). Huebner described a thorough analysis of the acquisition of the article $d a$ by his adult Hmong speaker. However. Thomas (1989) suggested that "Huebner's interest lies less in tracing the development of the native-speaker system of article usage than in depicting the systematicity inherent in his subject's interlanguage. This makes his results difficult to compare with more conventional work" (p. 340).

In her study. Thomas (1989) investigated the differences and similarities of $L 1$ and L2 patterns of article acquisition. Her subjects were 30 adult L2 learners placed in low. intermediate. and high ESL classes. Later on the participants were grouped according to whether or not their native language contained an article system. The group whose native language includes articles was classified as the $[+$ Art $]$ group. and the one whose language lacks an article system was named |-Art| group. Thomas used a paired story-telling activity in which a subject composed and narrated a story based on photographs to another subject. One participant played the role of the speaker. and the other played the role of the listener. The participants were seated back to back so that the listener could not see the pictures that 
were being described by the speaker. After a set of four pictures were described, the paired participants switched roles. Thomas taped the paired story-telling sessions, which lasted about 15-20 minutes. Then she analyzed the transcriptions of the tapes and recorded the occurrences of the, $a(n)$, and $\emptyset$ in each article context for each one of her participants. Thomas found that unlike LI learners. ESL learners did not demonstrate an early and accurate use of $a(n)$ in the $[-\mathrm{SK} .-\mathrm{HK}]$ contexts and the in the $[+\mathrm{SR},+\mathrm{HK}]$ contexts. Overgeneralization of $\emptyset$ in the and $a(n)$ contexts was the most common type of error committed by the L2 learners at all proficiency levels. Thomas explained that in L1 acquisition, this type of error only occurs in [-SR | situations, and in the early phases of acquisition. She believes that since the [-Art] group had a higher overproduction of $\emptyset$ than the $[+$ Art $]$ group, this difference between $\mathrm{L} 1$ and $\mathrm{L} 2$ acquisition of the articles may be caused by $L 1$ transfer. One similarity found between $L 1$ and $L 2$ learners is that while the is overgeneralized in the $[+\mathrm{SR},-\mathrm{HK}]$ first-mention situations, th is overgeneralization almost never occurs in the [-SR,-HK] situations. Unlike Huebner's study, Thomas' data did not show any signs of the-flooding in all NP contexts. In her study. Thomas added idiomatic expressions to Huebner's NP contexts, as did Butler (2002). Thomas concluded that throughout the acquisition of the articles in English, L1 and L2 learners tend to overgeneralize the in first-mention situations because they relate the with $[+\mathrm{SR}]$.

Another study by Hakuta (1976). investigated the order of acquisition of gram matical morphemes in the interlanguage of an ESL child. It depicted a 60-week longitudinal study of a 5-year-old Japanese girl acquiring English in a natural environment. Every two weeks. the subject's spontaneous speech was recorded while she was playing with her friends. The two-hour tapes were transcribed on the same day of the recordings. The order of acquisition of the grammatical morphemes was (1) present progressive. (2) didn't. (3) $3^{\text {rd }}$ person singular. (4) in. (5) to. (6) past progressive auxiliary was. (7) on. (8) did - interrogative. (9) 
doesn $i$, (10) possessive. (11) copula, (12) auxiliary, (13) articles, (14) $3^{\text {rd }}$ person regular, (15) past irregular, (16) past regular, and (17) plural. Hakuta's analysis of the articles included the and $a(n)$ only. He does not analyze the $\emptyset$ article. The results of the analysis of the and $a(n)$ demonstrated that these articles are acquired as a system, according to the subject's scores for presence of the articles in obligatory contexts $(90 \%)$. The articles were acquired late even though they appeared in the subject's speech frequently. Hakuta concluded that: "Clearly, salience of articles in English played a role, and articles appeared in her speech quite early. but without the proper discrimination necessary for full control” (p. 341). He argued that because the articles are absent in Japanese, his subject did not demonstrate full control of the semantics of these morphemes until much later.

Table 2-4 below displays a sum mary of the studies on the acquisition of English articles by L2 learners based on natural language production:

Table 2-4

Studies on the Acquisition of the Articles by L2 Learners Based on Natural Production

\begin{tabular}{|c|c|c|c|}
\hline Study & Articles examined & Tasks & Results \\
\hline Hakuta $(1976)$ & $\begin{array}{l}\text { - order of acquisition } \\
\text { of grammatical } \\
\text { morphemes in the } \\
\text { interlanguage of a } \\
\text { child learning ESL } \\
\text {-a/an, the }\end{array}$ & $\begin{array}{l}\text {-recordings of } \\
\text { spontaneous speech } \\
\text {-repeated every } 2 \\
\text { weeks for } 60 \text { weeks }\end{array}$ & $\begin{array}{l}-a(n) \text { and the } \\
\text { acquired late due to } \\
\text { absence of articles in } \\
\text { Japanese }\end{array}$ \\
\hline Huebner (1983) & $\begin{array}{l}\text { - developmental } \\
\text { stages of the article } \\
\text { system in an adult's } \\
\text { interlan guage }\end{array}$ & $\begin{array}{l}\text {-recordings of } \\
\text { subject's speech } \\
\text {-repeated every } 3 \\
\text { weeks for } 54 \text { weeks } \\
\text {-analysis based on } \\
\text { Bickerton's types of } \\
\text { NP Reference. }\end{array}$ & $\begin{array}{l}\text {-overuse and } \\
\text { overgeneralization } \\
\text { the (the-flooding). } \\
\text { - later amount of the- } \\
\text { flooding decreased } \\
\text { and subject used the } \\
\text { with }[+\mathrm{SR} .+\mathrm{HK}] \text { and } \\
{[-\mathrm{SR} .+\mathrm{HK} \mid \text { cases }}\end{array}$ \\
\hline
\end{tabular}




\begin{tabular}{|c|c|c|c|}
\hline Study & Articles examined & Tasks & Results \\
\hline Mizuno (1985) & $\begin{array}{l}\text {-types of errors made } \\
\text { by Japanese students } \\
\text { while acquiring the } \\
\text { articles in English }\end{array}$ & $\begin{array}{l}\text { - } 3 \text { objective tests: an } \\
\text { error-correction test, } \\
\text { a word arrangement } \\
\text { test, and a multiple } \\
\text { choice cloze test } \\
\text { - a productive test } \\
\text { (essay writing) }\end{array}$ & $\begin{array}{l}\text {-errors from } \\
\text { objective tests; word } \\
\text { order and co- } \\
\text { occurrence at } \\
\text { elementary stages. } \\
\text {-errors that } \\
\text { persisted in the } \\
\text { interlanguage } \\
\text { process: } \\
\text { underextension, } \\
\text { overextension and } \\
\text { substitution. } \\
\text {-production test } \\
\text { confirmed the } \\
\text { results, but errors of } \\
\text { underextension } \\
\text { more evident in the } \\
\text { essay tests } \\
\text {-errors of } \\
\text { overextension more } \\
\text { evident in the } \\
\text { cbjective tests }\end{array}$ \\
\hline $\begin{array}{l}\text { Tarone and Parrish } \\
\text { (1988) }\end{array}$ & $\begin{array}{l}\text { - NP Types elicited } \\
\text { across different tasks }\end{array}$ & $\begin{array}{l}\text { - grammar test (cloze } \\
\text { test) } \\
\text { - oral interview with } \\
\text { native speaker of } \\
\text { English } \\
\text {-oral narration task. }\end{array}$ & $\begin{array}{l}\text {-natural production } \\
\text { tasks had lower } \\
\text { number of errors } \\
\text { than cloze test } \\
\text {-article accuracy } \\
\text { varied depending on } \\
\text { the NP type and task }\end{array}$ \\
\hline Thomas (1989) & $\begin{array}{l}\text { - similarities and } \\
\text { differences between } \\
\text { L1 and } L 2 \text { patterns of } \\
\text { article acquisition }\end{array}$ & $\begin{array}{l}\text {-paired story-telling } \\
\text { activity }\end{array}$ & $\begin{array}{l}\text {-ESL students did } \\
\text { not show early and } \\
\text { accurate use of } a(n) \\
\text { in the }[-S K .-H K] \\
\text { cases and the in the } \\
{[+ \text { SR. }+H K] \text { cases. }} \\
\text {-overgeneralization } \\
\text { of } \emptyset \text { in the and } a(n) \\
\text { contexts. } \\
\text { - -Art] group higher } \\
\text { overproduction of } \varnothing \\
\text { than [+Art group } \\
\text {-no the-flooding }\end{array}$ \\
\hline
\end{tabular}


The studies based on data collected from $n$ atural production mentioned above seem to show how important it is to use natural production methods to assess the L2 learners' use of the English article system. Thomas' claim that cloze tests may provide an imperfect view of how learners use the articles is tested in Tarone and Parrish (1988) and Mizuno (1985). While Tarone and Parrish found that natural production tasks produce a lower number of errors related to article use than cloze type tests, Mizuno suggested that although the difference in results of objective and productive tests provide relevant in formation regarding the interlanguage process of the learner. these differences may also be linked to the different conditions that are forced upon the learners by these two distinct types of tests. Tarone and Parrish also argued that learners respond differently according to different tasks proposed to them. They attribute the difference in the article accuracy found in their study to the different communicative demands produced by the grammar test and the natural production tasks. Since the results related to accuracy of the articles seem to be inconclusive and since natural production tasks seem to provide a more complete perspective of article use by ESL learners. it would be in formative to examine the use of the articles in natural production tasks, such as dialogue journals.

\section{A Brief History of Dialogue Journals}

A dialogue journal is a regular in formal conversation between a student and a teacher. This com munication may occur on a daily or weekly basis, over a semester. an entire school year or the duration of a course. During the dialogue journal process students are supposed to write as much as they want. whereas the role of the teacher is to write back regularly, always replying to the questions and comments made by the students. The teacher also introduces new topics and asks questions in order to keep the written conversation flowing (Peyton. 1997). 
Staton (1988) reported on how the dialogue journal practice started. She suggested that the practice of interacting through written conversation may be connected to the beginning of writing itself. She explained that family members, co-workers. and students have been passing notes among themselves for generations. Moreover. for many years reports of the use of notebooks for interactive written conversations with students in the classroom for communication purposes have been noticed. However. Staton pointed out that it was only in 1979 that the first study on natural communication through written dialogues began in the classroom of Leslee Reed, a sixth-grade teacher in Los Angeles. California. In the mid 1960's. Reed gave her sixth-grade students the task of writing to her directly every day. She responded to the students ${ }^{\circ}$ writings every night. Reed realized that the success of the practice was the fact that she and her students kept the conversations private: therefore, she thought it was important to keep this practice quiet. Fifteen years later. Staton found out about Reed's successful classroom writing practice through a friend whose son was in Reed's class. Throughout the spring of 1979 Staton and Reed discussed the use of her written interaction method to help students write more functionally, aid in problem-solving and motivate personal growth. They were able to outline the differences between the traditional personal journal writing. in which the practice consists of a private "one way" written communication and the interactive written conversations that Reed used as a teaching strategy in her class. They eventually named the interactive written conversations dialogue journals.

Peyton (1986) reported that, years later, Mrs. Reed started teaching at a school in which $90 \%$ of the student population consisted of non-native English speakers. The dialogue journal practice became an important part in her teaching of a sixth-grade class comprised of 26 students from 12 different countries and 10 different language backgrounds. Through the dialogue journals Mrs. Reed was able to obtain important 
in formation about her students. as well as a way to help them adjust to the new culture. It also facilitated individualized instruction in a classroom with students from different cultures and languages and at different levels of English proficiency. Through the journals. Reed was able to interact with her students at their level of proficiency. In addition. the journals helped promote ESL language acquisition and improved the students "writing abilities through the modeling of language structures in written English (Peyton 1986). Benefits of Dialogue Journals

Dialogue journals give teachers the opportunity to expand "contact time with students getting to know them in a way that may not be possible otherwise." (Peyton. 1997 p. 46). The journals allow teachers to exchange ideas with the students about their personal interests. their mother linguage and culture, as well as problems adapting to the new culture. The continual feedback provided by the entries of the dialogue journals allows the teacher to have a glimpse of what students understand in class. as well as their language learning process. In addition to that. through the journals. the teacher obtains valuable information that can lead to personal individualized instruction based on the students' needs.

The focus of dialogue journals is basically on meaning and not on form. Even though the teacher's entries may be somewhat above the proficiency level of the students. the input given to them through the journals is comprehensible because it is based on real topics and issues that the students are interested in. The teacher models the correct forms and structures of the language providing the students with great exposure to the styles of a proficient English writer. As they keep writing and reading the teacher's entries. students begin to build up more confidence in their own writing skills (Peyton. 1997).

Staton (1987) summarized some of the major benefits of the use of dialogue journaling in the classroom: it creates opportunities for the students to natura!ly use the 
recent acquired language skills: it provides the students with opportunities to naturally and purposefully engage in different kinds of writing: it allows the teacher and the student to discuss academic and personal issues on a one-to one basis. and it lets the students reflect upon their experiences and think about concerns. ideas. and choices they are faced with every day.

The studies mentioned above described how the practice of writing journals emerged to aid and support the writing process. as well as some of the benefits provided by this learning strategy in the classroom. In addition to the studies described above. research on using dialogue journals with ESL learners has also been conducted.

\section{Studies on Dialogue Journals with ESL Students}

Lamb and Best (1990) suggested that through the use of whole language methods (e.g.. brainstorming with semantic maps. spontaneous conversations, writing folders. and dialogue journals) an ESL teacher is able to integrate natural language situations to promote L2 acquisition. They argued that effective ESL instruction should give emphasis to activities that are meaning-based, that focus on natural situations. and that are based on the students" previous experiences. One of the techniques they believe provides ESL students with natural language acquisition that is meaningful to them is the dia!ogue journal practice.

A study by Holmes and Moulton (1997) described the perspectives of L2 university students on dialogue journal use as a learning strategy. Six students in an intermediate ESL composition class were selected for the study. These students weekly journals and four indepth interviews served as data for the study. The researchers found three patterns concerning students" perspectives about dialogue journals: interpersonal perspectives. intrapersonal perspectives. and developmental perspectives. Two subgroups in the developmental perspective became apparent: writing fluency and motivation to write. Holmes and Moulton explained that the students perspective in their study validated 
Vygotsky`s (1978) claim that students imitate the instructor's language until they take in the structural forms and are able to lead themselves (learning through modeling of a more proficient speaker). The students in this study were able to write fluently and commun icatively: however, the researchers pointed out that their writings were not necessarily error-free.

Other studies have revealed that the use of dialogue journals in the ESL classroom promotes and improves language proficiency and natural language acquisition. For example, Dooley (1987) explored the instructional daily practice of dialogue journals in a class of Native American students living on an Indian reservation in Michigan over a period of 5 months. The subjects were 10 third-grade Native American students. They were second generation speakers of English. Most members of the tribe speak English: however, they used a dialect that resembled their native language and generaliy showed non-standard grammar and syntax. Students were asked to write a daily entry of at least 3 lines. The written conversations were confidential, and the journals were not graded. A month after the researcher began the journal practice: she presented the students with a two-part spelling teaching method. In the first part. the students were to circle the words they were not sure how to spell. The teacher helped them with the correct spelling of those words on the same day of the entry or in the written response. In the second part of the method. whenever the teacher noticed a word spelled incorrectly. she would make a note about it in the margin. The students were to correct the mistake and write the word in the" Word Bank" section of their notebooks. The teacher used the same correction technique for punctuation and capitalization errors. In addition to dialogue journaling. the teacher used a method called "controlled writing" in which the teacher dictates sentences for the students to write. These sentences often included words the students related to such as spelling words. vocabulary words. or words from their past experiences. After the students wrote the 
sentences in their notebooks. the teacher wrote them on the board so that the students could compare them with their own. The results demonstrated that sentence structure. punctuation. and grammar were improved in most cases. In addition. an improvement in the length of sentences and paragraphs was also noted.

An analysis of the acquisition of English morphology in the language used in dialogue journals of beginning ESL students is described in Peyton (1986). She suggested that dialogue journals provide relevant conditions for second language writing acquisition based on the fact that students, even at the early stages of acquisition, can produce some kind of written communication in the journal. In addition. more advanced students are able to write freely about topics that are relevant to them and receive responses that are in formative and appropriate for their proficiency level. Moreover, according to Peyton, the journals have characteristics that resemble interaction between "a child learning a first language and a caregiver and between second language learners and native speakers of that lan guage in informal context" (p. 4). Thus. Peyton argued that the dialogue journal practice can provide a beneficial environment for $\mathrm{L} 2$ writing acquisition in a context that resembles natural oral interaction.

However. important questions regarding this matter are raised: Is there evidence of language acquisition of beginning ESL learners over time? What are the acquisition patterns of dialogue journaling? Are acquisition patterns in dialogue journals specific to one student or are these patterns common among students? Even though grammatical morphology represents only a small part of language acquisition. Peyton decided to focus this study on the acquisition of six verb-related morphemes (regular past. irregular past. progressive -

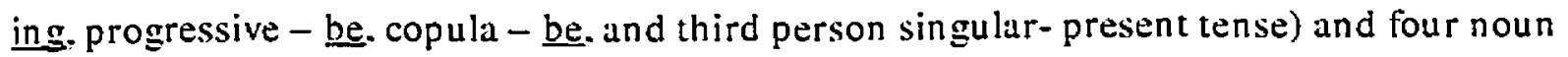

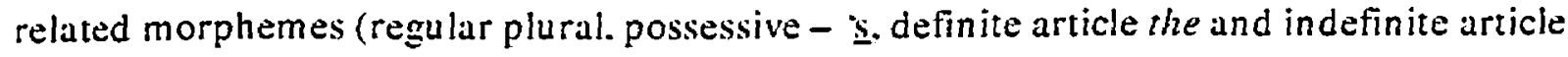
a) in the dialogue journals. The morphemes mentioned above were chosen because as 
Peyton read the journals. she noticed they stood out as part of the students" developing language competence. The participants in this study were from two sixth-grade classes of ESL learners. The teacher was Leslee Reed. who. as mentioned before in this literature review. started the practice of communication through written dialogues.

Five students from Reed's two different classes were selected for the study throughout the 1980-81 and 19S1-\$2 school years (two periods of 10 months). These students were selected because they were beginning ESL students. Their native languages were Burmese. Italian and Korean. One of them. however, had moved from Korea to Brazil when he was five years old and lived in Brazil for seven years before moving to the United States. Therefore. the participants in this study were five students from four different language backgrounds: two Koreans. one Burmese. one Italian and one Korean with Portuguese as a second language.

First. Peyton divided the 10 months into sample periods (fall. winter and spring). with each sample period consisting of 20 interactions. For each sample she analyzed the occurrence of the six verb-related morphemes and four noun-related morphemes in the journals written by the students. For each morpheme supplied in the context. a score of 1 point was given. If the morpheme was not supplied, a score of zero was given. The total number of morphemes supplied was divided by the total number of contexts in which it should have been supplied, per individual performance score. After that she summed the scores of the five students in two ways: the Group Score was the sum of the individual ratios. and the Group Mean was the sum of individual percentages derived from the ratios. The information obtained from the group performance scores allowed the researcher to rank these scores from highest to lowest. The results showed that the rank orders for the chosen morphemes for the five students as a group are similar among the sample periods and that 
the rank orders among individual students are also similar to the ones found in other studies.

Peyton's analysis did not stop there. She was also interested in the acquisition patterns in the dialogue journals of individual students over the three sample periods. For that reason. she decided to conduct a longitudinal analysis of the data obtained from the journals. The results showed a great deal of variation in the individual students" use of the selected morphemes. The use of the articles revealed interesting patterns of acquisition. Peyton. like Hakuta (1976). separated the analysis of the articles into definite and in definite (as opposed to other researchers who had treated the articles as a single category in many studies related to the acquisition of morphemes). In studies in which articles are considered a single category, they rank high in the order of acquisition. when they are separated into defin ite and indefinite: however. the patterns of use are very different. The correct use of a ranked far behind the correct use of the. Peyton also found that the use of articles. overgeneralization and the use of possessive - $\underline{\text { seflected transfer from the individual }}$ student sirst language. This confirmed results from Hakuta's (1976) analysis. In addition. students whose previous language contained an article system (Portuguese and Italian) achieved $100 \%$ of accuracy by the end of the school year. whereas students whose previous languages did not have articles (Korean and Burmese) were never able to reach $90 \%$ accuracy. In order to obtain the individual student's total control of use of articles (as opposed to use only in obligatory context) Peyton used the same method as Hakuta (1976). in which he divided the number of times the article is used in correct contexts by the total number of article occurrences. Peyton made important conclusions regarding her study: some morphemes were mastered rapidly by the studen ts while others demonstrated no relevant gain over time: first language transfer caused great variation in the acquisition process of individual students; language proficiency is improved as a result of the use of 
dialogue journals over time; and ESL students are able to write and express them selves in English even before they thave acquired the forms and structures of the language.

The research on dialogue journals presented above seemed to validate not on ly the benefits this technique provides to social interaction between a teacher and her students. but the benelits this practice provides to language acquisition of ESL students. Dooley's (1987) analysis is important to this present study because it showed an improvement in the students" sentence structures. grammar. and writing skills over time due to the dialogue journal practice as well as other techniques. Peyton (1986) provides a very thorough analysis of the acquisition of English morphemes (including English articles and possessive - s) in the dialogue journals of ESL students. which will together with other studies serve as basis to the analysis that will be performed in this present study. The dialogue journal studies are also relevant because they expand research on article use in different productive tasks as discussed in Tarone and Parrish (1988) and in Mizuno (1985) as well as research on article use by [-Art ] language speakers. Since there are conflicting results regarding accuracy of the article use in natural production tasks, this present study will exam ine the use of the articles and other determiners by Japanese |-Art| students of ESL in their dialogue journal entries (as a productive task). Thus. the accuracy of these students' article usage in an integrated linguistic activity (dialogue journals) will be investigated.

In conclusion. this review of literature provided an explanation of the article system in English. an analysis of second language acquisition studies of article learning by Japancse learners of English as well as a description of the benelits of the use of dialogue journals in the classroom. A summary of the issues discussed in this chapter is presented below.

The articles are among the most commonly used words in the English language. Nonetheless, their usage seem to be quite complex due to the different article forms. different noun categories, and the different NP contexts that have to be taken into 
consideration when making the correct article choice. The articles belong to a class of grammatical items called determiners. The use of the three different forms of the English articles $(a / a n$, the, and $\emptyset)$ varies according to the noun they accompany. The different categories of the English nouns (proper. common. count, noncount. concrete. and abstract) are affected by certain features such as, number. deliniteness, and countability. In addition. the English articles also describe noun phrase referentiality. Noun phrase reference is represented by two discourse features $1+1-$ SR. HKI. These binary features cause four basic NP environments. which can be related to one or more article choices. depending on the number. deliniteness. and countability characteristics of the noun. As explained earlier. all of those clements must be considered in order to make the correct choice of the article. This can make the use of the articles quite complex. especially for [-Art] ESL learners.

Regarding the acquisition of the articles, studies such as Yamada and Matsuura (1982) showed that the difficulty order of the English articles was different depending on the proliciency levels of the students. Butler (2002) revealed that article accuracy is higher for more proticient learners. Mizuno (19S5) demonstrated that different proficiency levels produce diflerent types of article errors. Article accuracy is also in lluenced by the different types of tasks proposed. Tarone and Parrish (198S) found higher article accuracy in natural production tasks (oral narrative and interview) than in objective tasks (grammar test). Mizuno (1985) also found that diflerent tasks elicit different types of article errors.

There are several factors that seem to affect the acquisition of the articles. Master (19S7) suggested that the presence or absence of the articles in a learner's Ll, seems to in fluence the manner in which this learner will acquire the English article system. [+Art] learners are one level of acquisition ahead of [-Art l students. Therelore. the lack of an article system in a learner's Ll can also cause challenges for the use of the Englisin articles by this learner. Hakuta (1976) hypothesized that overtly marked forms (salient forms). such as the 
articles, are acquired early. However, since his subject? Ll was Japanese, and the distinction of speciftel non-specific is not marked in this language. the articles were acquired late regardless of how salient the forms are. Thomas (1989) found that her L2 learners. unlike Ll learners, very frequently made errors of overproduction of the $\emptyset$ article (omission of the, and $a / a n$ ). at all proficient levels. Because these errors were more frequent for her [-Art] group than for her [+Art] group. Thomas argued that Ll transfer possibly causes the difference between L1 and L2 acquisition of the articles. Peyton (1986) found that [+Art] learners had a higher accuracy of the articles over time than her [-Art] students. She suggested that these findings were caused by the in dividual student's Ll.

Linguistic context seems to be another factor in the acquisition of the articles. Takahashi (1997) discovered that answers in a cloze test and a multiple choice article insertion test were more accurate when the NP modified by a relative clause required the than when it required a/an: and that the use of the was more accurate in common language use (idioms) than in non-common language use. Yoons (1993) lindings showed that noun countability is viewed differently by speakers of the same language. and that perceptions of noun countability between her native English speakers and her J apanese speakers were reversed. She concluded that context must be considered when determining whether a noun is countable or uncountable. Another factor that seemed to altect article acquisition was referentiality of the NP expressed through $\mid+/-\mathrm{SR}$. HKI leatures. Referentiality and noun countability were great problems for the students in the Butler (2002) study. since they prevented the participants from making the right article choices.

Another interesting circumstance that may affect the article acquisition is the claims made by Mizuno (1985) and Tarone and Parrish (19SS) regarding how different tasks can affect the learner"s attention to the use of the articles. While Mizuno suggested that students tend to monitor the use of the articles more in an objective task (grammar test). Tarone and 
Parrish, on the other hand. argued that in order to communicate meaning in an integrated linguistic task (narrative. or composition). students must mark the article forms correctly in certain types of NP so that the listener can follow the progress of this type of task. Since both Mizuno's and Tarone and Parrish s claims seem inconclusive. it would be in formative to in vestigate the accuracy of the use of the articles in a natural language production activity (in an integrated linguistic task).

A learning sirategy that seems to promote natural language production is the use of dialogue journals. Staton (1988) suggested that dialogue journais are natural and in teractive written conversations that can be used as an effective teaching strategy in the ESL classroom. Some of the benefits pointed out by Peyton (1986) are that the students" writing skills are improved through modeling language structure produced in the journals and that the journals provide opportunities to interact with the students at their proficiency level. In addition. Lamb and Best (1990) claimed that the journals promote L2 acquisition through meaningful communication. Dooley"s (1987) study revealed an improvement in the students"use of grammar, punctuation, and sentence structures. Peyton`s (1986) findings indicated that the use of the was more accurate than the use of a/an in the journals and that language proliciency is improved through the journals over time.

Several questions are raised by the literature reviewed in this chapter. Since the use of the English articles is complex, especially for [-Art\} learners, and dialogue journals seem to improve language proficiency and natural language acquisition, how would Japanese ESL students [-Art] use the articles in all integrated linguistic activity. such as the dialogue journal practice? What would the accuracy level of article use be? What types of errors would the Japanese students make in their journals and why? Based on the questions raised by this chapter and on the analyses and results discussed in this review of fiterature. I find it useful to examine these questions. 
The reseurch design and methodology used in this present study is discussed in the next chapter. 


\section{Chapter 3}

Research Design and Methodology

This study was designed to examine the general characteristics of the use of the English article system and other determ iners by Japanese students of ESL as demonstrated by the entries in their dialogue journals. As mentioned in the previous chapter, studies on article acquisition based on data collected from cloze tests may offer an incomplete view of how the students actually use th is complex system. A few studies on article use in natural production have been conducted. One teaching strategy that seems to improve the students' use of grammar. punctuation. and sentence structure over time within natural and meaningful language use is the dialogue journals. However. no research on dialogue journals specifically describing the use of English determiners seems to have been done.

As one reads the research on the acquisition of the English article system by ESL learners. as well as the research on dialogue journals. relevant questions arise:

(1) How do J apanese ESL students use the English articles. as well as other determiners. in natural language production. such as the entries of their dialogue journals?

(2) What is the level of accuracy of determiner use?

(3) What errors do Japanese ESL students make when using the articles and other determiners and why?

This chapter is organized as follows: fîrst, I provide information regarding the research questions and descriptions of the setting and the participants. Second. I give a report on the materials used to collect the data. as well as a detailed description of the procedures. Finally. I depict the coding system used in the study. 


\section{Setting}

The data for this study were collected at a small private liberal arts college in the United States. The total student population of this college is about nine hundred, and the college's international student population is comprised of 46 students from 20 different countries. These forty-six international students comprise approximately $5 \%$ of the total student population. In order to be accepted at this institution. international students must have a minimum TOEFL (Test Of English as a Foreign Language) score of 500 for the paper-based test or 173 for the computer-based test.

In this private college, the 46 international students were en rolled in the 30 undergraduate courses offered by the institution. Twenty-two students out of the 46 were new to the college. During the fall semester of 2002,12 out of the 22 new international students at this institution were en rolled in an ESL course, which emphasizes the listening. speaking. reading. and writing skills needed by any international student to function satisfactorily in an American college setting. These 12 international students were the initial volunteers for this study.

\section{Participants}

The initial volunteers for this study were 12 international students en rolled in the ESL course. The group consisted of eight females and four males. Their age range was between 19 and 23. These volunteers were all Asian: 10 from Japan. one from South Korea and one from Myanmar. Therefore. the group of in itial volunteers consisted of $10 \mathrm{~J}$ apanese speakers. one Korean speaker. and one Burmese speaker. Most of the volunteers were transfer students from colleges in their own countries. Thus, 11 of them were in their second year of college, and only one was in his lirst year of college. The participants" TOEFL scores ranged from $500 / 173$ to $573 / 230$. 
At the end of the semester, the instructor selected the final 6 participants out of the 12 participants that in itially volunteered for the study. Since the study focused on the description of the English articles as determined by the entries of J apanese ESL students* dialogue journals. the data collected from the two participants whose native language were not $J$ apanese were eliminated from the project. In addition, in an attempt to make the data more appropriate for the study and to ensure that the data were as representative of as possible in terms of the gender (equal number of males and females), age and TOEFL scores among the students in the ESL class, the journals of four other participants were extracted from the project. Table 3-1 below presents the final list of participants for this study.

Table 3-1

Student Information - Final List of Participants

\begin{tabular}{llllll}
\hline Participant & Gender & Age & $\begin{array}{l}\text { County } \\
\text { of Birth }\end{array}$ & $\begin{array}{l}\text { Native } \\
\text { Language }\end{array}$ & $\begin{array}{l}\text { TOEFL } \\
\text { Test } \\
\text { Score }\end{array}$ \\
\hline Student 1 & female & 20 & Japan & Japanese & $500 / 173$ \\
Student 2 & female & 23 & Japan & Japanese & $500 / 173$ \\
Student 3 & male & 20 & Japan & Japanese & $500 / 173$ \\
Student 4 & female & 19 & Japan & Japanese & $520 / 190$ \\
Student 5 & male & 20 & Japan & Japanese & $550 / 213$ \\
Student 6 & male & 20 & Japan & Japanese & $573 / 230$ \\
\hline
\end{tabular}

Research Method

The dialogue journals of the participants were used as the main source of data for this study with the aim of describing and analyzing the use of the English determiners in the journal entries of J apanese ESL students. The data were collected over a period of eight weeks during the fall term of 2002. More details on the collection of the data are found in the description of the procedures. 


\section{Procedures}

This research project was carried out in a low-advanced multi-skill ESL class. The class met three times a week on Mondays. Wednesdays. and Fridays for 55 minutes. At the beginning of the fall semester, the students were told that one of the tasks that would be carried out in the ESL class they were taking was the dialogue journal practice. The instructor, who is aiso the researcher of this project. explained that the dialogue journal is an informal ongoing written conversation between the students and the teacher. She told them that they would develop and maintain this ongoing written conversation throughout the entire semester.

According to Staton, Shuy. Kreeft, and Reed (1988), in the beginning of the dialogue journal process, the teacher should not be concerned with the content of the first entries because it usually takes a couple of months for the students to "get going" with the process. For that reason, the researcher wanted the students to get used to dialogue journaling before collecting data for the study. The instructor assured that the students understood the privacy surrounding dialogue journals. She explained that the written conversations should belong only to the two writers and that the information in the entries should not be shared without the consent of both of them. After that, the instructor brainstormed some of the topics the students would like to talk about. Then. the students were allowed some time to ask questions about the dialogue journal process. After answering all of the students' questions. the researcher gave out spiral notebooks to the students and told them that they would use them to write the journals. She explained that they were supposed to take the notebooks home every Friday, write down their entries over the weekend, and return the notebooks to the teacher every Monday.

A month later, the students were in vited to participate in the research project. The researcher explained to the students that she was interested in learning how dialogue 
journals im prove ESL learners' skills. The students were never told that their use of the English article system and other determiners in the dialogue journals was being investigated. In addition, the researcher told the students that their participation in the project was voluntary: therefore. their refusal to take part or withdraw from the study would have no bearing whatsoever on their grades in the ESL course or any other course in which they were enrolied. She also told them that the journals would be kept anonymous and confidential. After that. the students were asked to sign a letter of consent. All 12 students in the ESL course agreed to participate in the study.

In week six of the fall semester. at the beginning of the class. the students were asked to answer a questionnaire that included a list of questions regarding the participants English learning background. The questionnaire used in the research consisted of 20 questions (Appendix A), which focused on the students English learning background. The questionnaire was given to all the students enrolled in the ESL course. The main purpose of the questionnaire was to gather information on the students ${ }^{\circ}$ experiences as ESL learners, as well as their language learning strategies and to assist in the selection of the final participants for this current study. The instructor administered the questionnaire in class. and it took the students approximately 20 minutes to complete the task. From that day until the end of the semester the data for the research project were collected.

\section{Data Collection}

Every Friday the students took the spiral notebooks home. wrote their journal entry. and returned the notebooks to me on the following Monday. In order to write the entries, the students were instructed to answer the question proposed by the teacher, as weil as to ask as many questions as they wanted each week. I decided to start the conversations. providing the students with an initial topic for each entry. so it would make it easier for them to write back to me. I found that. as the students became more involved in the journal 
process. they developed the initial topic more. added their own opinions on the subject and introduced new ideas in which they were more interested in. This is consistent with Staton (1988), who states that "topics change. merge. and become elaborated as each participant comments on the topic, adding new, relevant information which successively changes the topic of discussion" (p. 13). She explained that one of the roles of the teacher is to enhance and remodel the students" topics into more detailed and complex ones. The students were free to write in their entries as much as they wanted throughout the eight weeks the journal process was conducted. Even though the data collection was in an established ESL class. corrective feedback was not given on the students' article usage.

The main data for this current study consisted of the photocopies of the journal entries of six Japanese students in my ESL class kept during a period of eight weeks. Therefore, since each student wrote one entry per week, a total of 48 entries were analyzed in the study (eight entries per student). The teacher's entries were not counted or analyzed in the study. The photocopies of the entire text of each student entry were then combined to form six student journals. which were numbered from student one to student six. In the same manner. the entries in the students journals were numbered from entry one to entry eight. The students and the entries are referred to by using the number system explained above (e.g., Student 3, entry 5). Once the selected entries were organized in to the six journals, the researcher coded the data. An explanation of the coding system is described below.

Description of the Coding System

In order to describe the use of the English article system, as well as other determiners, as dem onstrated by the dialogue journal entries, the data needed to be first coded and analyzed. The researcher first identified every NP by highlighting every noun in each of the participants' entries. After that, these NPs were numbered in every student 
entry. This was done in order to facilitate the documentation of the usage of the English articles in the students' dialogue journals.

An article log was used to record the NPs used by the students. The researcher used one article log per entry. per student. Since there were six students and each student wrote eight entries in their journals. a total of 48 article logs were used to record the data. Column one in the log was used for entering the NPs, while column two was used to record the possible context for the article used with that particular noun and to identify whether that specific article was used correctly or incorrectly by the student. To be more specific. the articles used by these students in their entries were categorized as whether there was a context for the. $a / a n . \varnothing$ determiner. possessive $(P)$. and other determiner (Other Det.). In addition. the article log recorded whether these articles were used correctly (acceptable in Standard English) or incorrectly (not acceptable in Standard English).

For the purpose of this study, the English determiners used by the students were divided in to NP categories based on their context of use. The articles $a / a n$. the, and $\emptyset$ each belong to their own NP category. My, your. whose. their, her, etc are in the possessive (P) category. while each. much, any. most, this. etc are included in the other determiner (Other Det.) category. Throughout the coding process. the researcher observed frequent problems such as the use of a singular noun with a plural verb and vice versa (c.g.. there are huge interval...). These problems were also documented in the article log and classified as noun form (NF) problems. In addition. a specific category was created for gerunds (e.g.. $M y$ mother is good at sewing.) and other problems. For example, sentences that did not make sense in Standard English were classified as problem (e.g.. She said Japanese people need to make eye contact much more time even now. Compound nouns were counted as one single NP (e.g.. a junior high school student). Formulaic speech (e.g., in addition. in conclusion, etc.) were also counted as a single NP. 
The coding system described above was used to analyze the data collected for th is study. However. in order to assure that this system was appropriate for the research project and that the researcher used the system adequately. a subset of the data was coded and analyzed for interrater reliability. Based on the coding system depicted above. a training set of dialogue journals obtained from two Japanese volunteer students that were previously eliminated from the study were coded by the researcher and a native speaker of English. Eight entries of the dialogue journals from each student were analyzed. A total of 261 NPs were coded. The number of coded NPs agreed on by the researcher and the native English speaker was 245 . The formula used to obtain the percentage of agreement was: number of coded NPs agreed on divided by the total number of NPs coded. The percentage of agreement attuined based on the coding system was $93.86 \%$. Th is number was judged to indicate a sufficient degree of agreement between the two coders. The disagreements in the coding of the training sets were resolved through discussion and clarification. Based on the coding system and the discussions and clarifications in coding made during the interrater reliability procedure, the entries from the remaining six J apanese students selected for this study were coded by the researcher alone.

Peyton 's (1986) analysis of the individual students' total control of the use of the articles. which was based on Hakuta's (1976) method to calculate mastery of the use of morphemes. employs the following formula: number of correct articles divided by the total number of articles used by the students. This formula seems to fit the definition of accuracy order provided by Hatch (1978). in which she explains that what is measured in a crosssectional study is the percentage of times a participant provides a grammatical item correctly in obligatory contexts (p. 379). For the present study, th is same method to calculate the percentage of correct usage of the English articles. as well as other determiners was used. 


\section{Data Entry and Organization}

In order to ensure data integrity, reduce data redundancy, and provide query tools for assembling summary charts. a database program was elected lor data entry and organization. The database consisted of five tables. which had a th ree tier hierarchy for data entry. The tables had primary keys associated with their parent tables. along with one-tomany relationships to eliminate the possibility of duplicate entries. The Students table represents the first and primary table which was keyed to the student number. The Entry table was used to keep track of the students" entries and was keyed from the parent table Students. The main data entry table was called Noun-Phrase. and it had a loreign key derived from the parent Eniry tabie. One important field in the Noun-Phrase table was the NP number. which corresponded to the number of NPs used by the student. per entry. In addition, two look-up tables were created to aid in the data integrity and reduce data errors by restricting the list of options to select from when entering the data. The Noun-Phrase Category table included a list of all NP categories analyzed in the study. and the Correct table displayed the options for the correctness of the determiners used by the students. The options were: Yes (when the students supplied the determiners correctly in obligatory contexts). No (when the students supplied the determiners incorrectly in obligatory contexts), and N/A (when correctness was not applicable - e.g.. Problem or Noun Form categories). This data entry lorm was the primary form used to en ter the data. The following chapter presents a detailed explanation of the findings encountered in the collection of the data lor this research project. 


\section{Chapter 4}

Findings

The purpose of this chapter is to report on the use of English articies as well as other determiners by Japanese students of ESL as manifested in the entries of their dialogue journals. As discussed in chapter 2. the $\mathrm{major}$ questions with which th is study is concerned are the following:

(1) How do Japanese ESL students use the English articles, as well as other determiners in natural language production. such as the entries of their dialogue journals?

(2) What is the level of accuracy of determiner use?

(3) What errors do Japanese ESL students make when using the articles and other determiners and why?

In order to lind the answers to these questions. three different analyses of the data collected, organized. and coded in the manner explained in chapter 3 were conducted lor this study. Analysis 1 exam ined the use of a/an. the, $\emptyset$. possessives, and other determiners in the Japanese students" dialogue journal entries. In Analysis 2. the determiners used by the students were grouped and described according to the three classes of English determiners proposed by Master (1993) and Greenbaum and Quirk (1990): predeterminer. central determiner. and postdeterminer. In Analysis 3. the errors made by the students were analyzed according to the live types of errors described in Mizuno (19S5): co-occurrence. word-order, underextension, overextension, and substitution. In addition. the errors were analyzed according to the NP Types proposed by Huebner (1983) and Bickerton (1981): Type 1 l-SR, +HKI. Type 2 |+SR. +HK]. Type 3 I+SR. -HK], and Type 4 |-SR. -HKI: as well as Type 5 (Idioms) proposed by Thomas (1989) and Butler (2002). The results of the lirst 
analysis of the use of the determiners in the Japanese students" dialogue journals were described in terms of total NP occurrences: types of determ iner used. and correct individual student use. The results of the second analysis were described in terms of total NP occurtences (according to the English determiner classifications) and correct individual student use. The results of Analysis 3 were described according to the Mizuno: (19S5) error classifications and the 5 NP Types explained in chapter 2. Below is a detailed description of the lindings related to Analysis 1. Analysis 2. and Analysis 3.

Analysis /

As mentioned earlier, the use of a/ an, the. $\emptyset$. possessives, and other determiners in the J apanese students dialogue journal entries was examined in terms of total number of NP occurrences per student, types of determiners used, and correctness. The results of th is lirst analysis are presented below.

Total number of NP occurrences per student.

The total number of NP occurrences per student is illustrated in Figure 4-1. The pie chart below reveals variations in the number of NP occurrences among the six Japanese students. Student 6 wrote the highest number of NPs, 3 19: followed by Student 3 with 3 is occurrences documented. The number of NPs decreases considerably lor Student 1 with 220 and Student 2 with 209 occurrences. Student 4 had 187 instances of NPs. while Student 5 had the lowest number of occurrences. 172. 
Figure 4-1

Total Noun Phrases per Student

\section{Total Noun Phrases per Student}

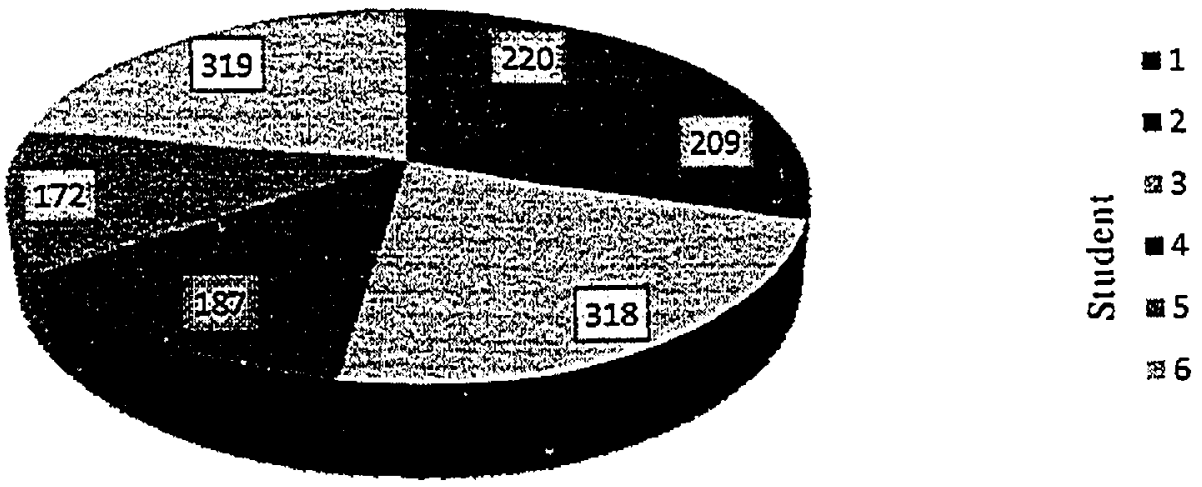

Table 4-1 below displays the number of NP oceurrences for eacin student journal entry, as well as each student's average NP instances for all eight journal entries. Student 5 and Student 4 had the lowest average of NP occurrences per entry. 22 and 23 respectively. Student 2 had an average of 26 occurrences per entry. while Student l's average was 28. Student 3 and Student 6 had the highest average of NPs with 40 occurrences per journal each. Since dialogue journals are on going in formal written conversations between the students and the teacher, the length of the journal entries and the number of NP occurrences could not be controlled by the rescarcher. This is important to point out because the more the students wrote in the dialogue journal entries: the more they created opportunities to use the English determiners in natural language production and thus polentially make more mistakes. 
Tabie $4-1$

NP Occurrence per Entry

\begin{tabular}{|c|c|c|c|c|c|c|c|c|c|c|}
\hline & & & & Entr & & & & & Tot & $A$ \\
\hline & 1 & 2 & 3 & 4 & 5 & 6 & 7 & 8 & & \\
\hline Student i & 26 & 25 & 40 & 13 & 22 & 29 & 56 & 9 & 220 & 28 \\
\hline Student 2 & 43 & 23 & 39 & 25 & 13 & 21 & 30 & 15 & 209 & 26 \\
\hline Student 3 & 28 & 57 & 56 & 27 & 42 & 39 & 33 & 36 & 318 & 40 \\
\hline Student 4 & 29 & 21 & 40 & 21 & 13 & 32 & 14 & 17 & 187 & 23 \\
\hline Student 5 & 34 & 24 & 18 & 20 & 14 & 31 & 17 & 14 & 172 & 22 \\
\hline Student 6 & 36 & 12 & 129 & 11 & 52 & 21 & 52 & 6 & 319 & 40 \\
\hline Totals & 196 & 162 & 322 & 117 & 156 & 173 & 202 & 97 & 1425 & \\
\hline
\end{tabular}

Types of determiners itsed.

The types of determiners analyzed in Analysis 1 were a/an, the. 0 . possessive, other determiner. gerund, problem. and noun form. For the purpose of this study. I refer to their occurrences with a noun as NP categories, each of them belonging to a separate NP category. Table 4-2 provides a breakdown of student NP occurrences for each NP category. The articles $a / a n$. the. and $\emptyset$ comprised the majority of the determiners used in the Japanese students journal entries. The $\emptyset$ articie has the most occurrences $(470)$. lollowed by the with 228 and $a / a n$ with 216 occurrences. The possessives follow the articles with 197 occurrences. The other determiners (e.g., each, much. any, most, this. etc.) category had a tolal occursence count of 133 . Followed by noun form with $\$ 2$ instances. Sixty-eight instanees of gerunds were counted and only 31 occurrences ol problems were lound. Figure 4-2 graphically depicts the data presented in Table 4-2. 
Table 4-2

Noun Phrase Breakdown per Student

\begin{tabular}{|c|c|c|c|c|c|c|c|}
\hline \multirow{2}{*}{ NP Citegory } & \multicolumn{6}{|c|}{ Student } & \multirow{2}{*}{ Total } \\
\hline & 1 & 2 & 3 & 4 & 5 & 6 & \\
\hline$a / a n$ & 32 & 32 & 32 & 32 & 42 & 46 & 216 \\
\hline the & 35 & $2 S$ & 65 & 17 & 19 & 64 & 228 \\
\hline$\varnothing$ & 78 & $6 S$ & 92 & 66 & 51 & 115 & 470 \\
\hline possessive & 31 & 38 & 43 & 28 & 17 & 40 & 197 \\
\hline $\begin{array}{l}\text { other } \\
\text { determinar }\end{array}$ & 17 & 20 & 28 & 24 & 22 & 22 & 133 \\
\hline noun form & 8 & 15 & 23 & 15 & 13 & $S$ & $\$ 2$ \\
\hline gerund & 16 & $i$ & 26 & 2 & 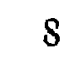 & 15 & 68 \\
\hline problem & 3 & 7 & 9 & 3 & 0 & 9 & 31 \\
\hline
\end{tabular}

Figurs 4-2

Noun Phrase Breakdown per Student

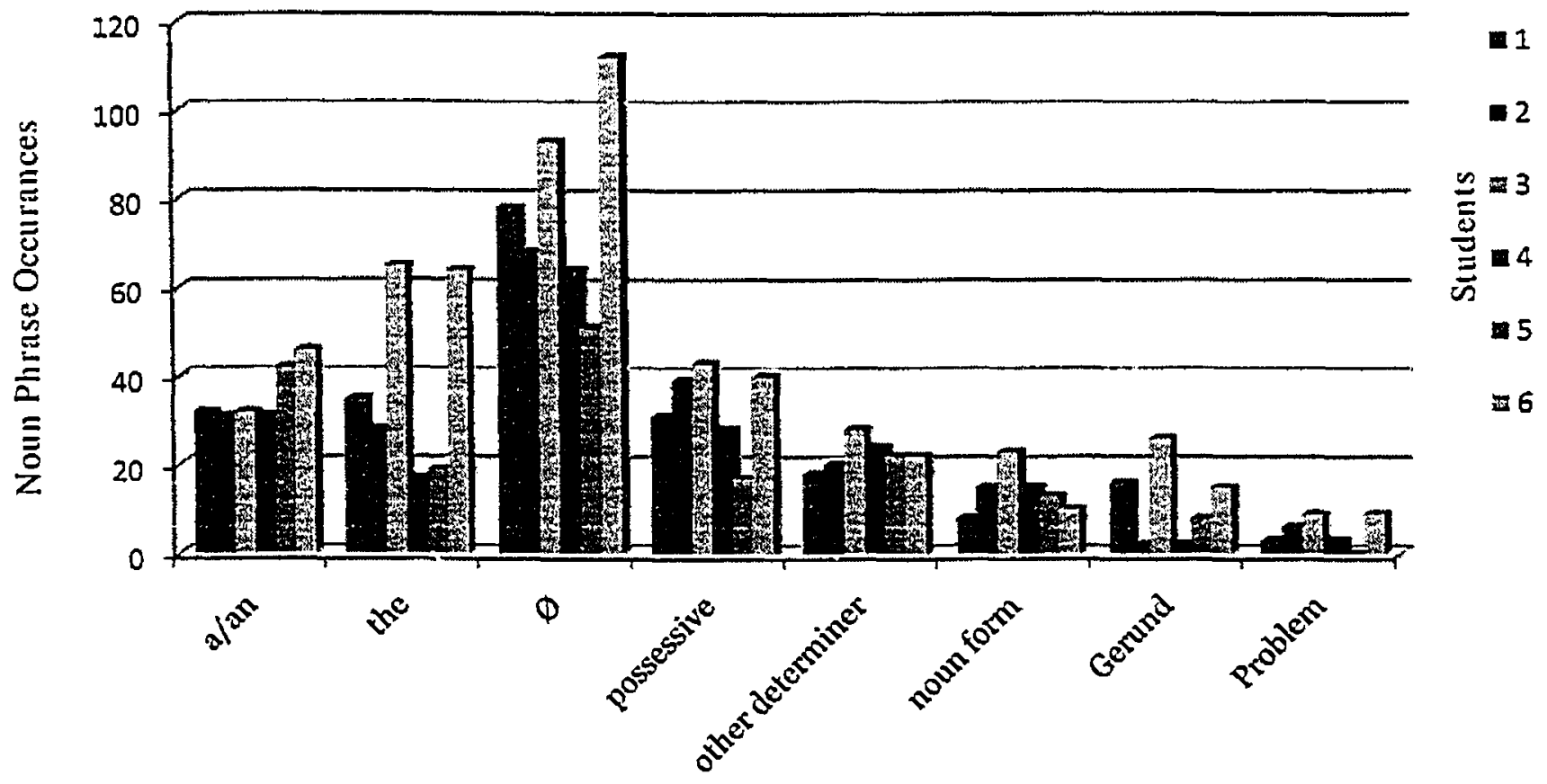

Noun Phrase Type 


\section{Correctness of the determ iners used.}

In order to establish the individual student's total control of the use of the English determiners. the same method employed by Peyton (1986) and Hakuta (1976) was used. In this method the number of occurrences of the articles in correct contexts is divided by the total number of article occurrences. The in dividual student use of the English determiners, as well as a sum mary of the overall correctness of the use of the determiners for Analysis 1 are documented and discussed below. Table 4-3 demonstrates the summary of the overall correct use of the determiners by the participants.

Table 4-3

Overall Correct Determiner Use

\begin{tabular}{lrr}
\hline NP Correct & Occurrences & $\%$ \\
Summary & 1.022 & $72 \%$ \\
\hline Correct & 222 & $15 \%$ \\
Incorrect & 181 & $13 \%$ \\
N/A & 1.425 & $100 \%$ \\
Total & & \\
\hline
\end{tabular}

The results show that 1.022 out of $1.425(72 \%)$ occurrences of the English determiners used by all the six participants in the study were used correctly. The number of determiners used incorrectly was 222 . or $15 \%$. All the instances of noun form and problems were marked as N/A (not applicable) in the database and were excluded from the analysis performed in the study. The reason for this is that. since the noun form category represented the use of an incorrect noun form. the choice of the article with it may misrepresent the learners" understanding of the article system. Also, in order to determine if the use of gerunds had an effect on the number of article errors made by the students, they were coded separately. All 
the occurrences of gerunds found in the data were in stances of the $\emptyset$ article used correctly. However. the gerunds were also excluded from the analysis of correctness and marked as $\mathrm{N} / \mathrm{A}$ in the database although their inclusion would increase the overall percentage correct by $5 \%$ (i.e.. 77\% correct). Figure $4-3$ illustrates the percentages of correctly used NPs (yes). in correctly used NPs (no). and non-analyzed NPs (N/A) according to the numbers obtained from the data analysis.

Figure 4-3

Noun Phrase Correciness

\section{Noun Phrase Correctness \\ Summary}

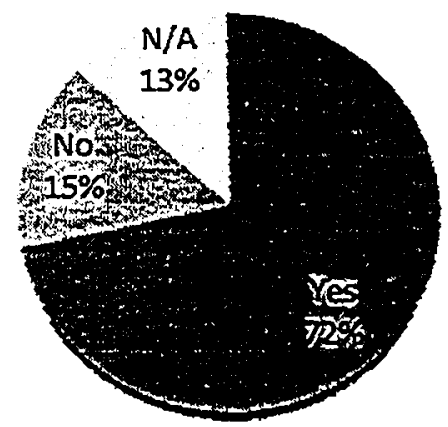

Next. I turn to the results of each individual student's use of the English determiners. calculated according to the method explained above. They are presented in Figure 4-4 below. When we look at the overall percentages of the determiners used by all six of the students. we notice that the articles $a / a n$ and the had the lowest overall percentage of correct usage. $50 \%$ and $62 \%$. respectively. The a verage percentages of the remaining types of determiners were much higher than the ones for $a / a n$ and the. Other determiners were used correctly $95 \%$ of the time. The level of correct usage of possessives reacled $96 \%$ and $\emptyset$ had the highest percentage of accuracy among the determiners analyzed with $97 \%$ correct. 
Figure 4-4

Percentage of Correct Determ iner Usage

Determiners: Percent Correct

Individual Students \& Total Average Correct

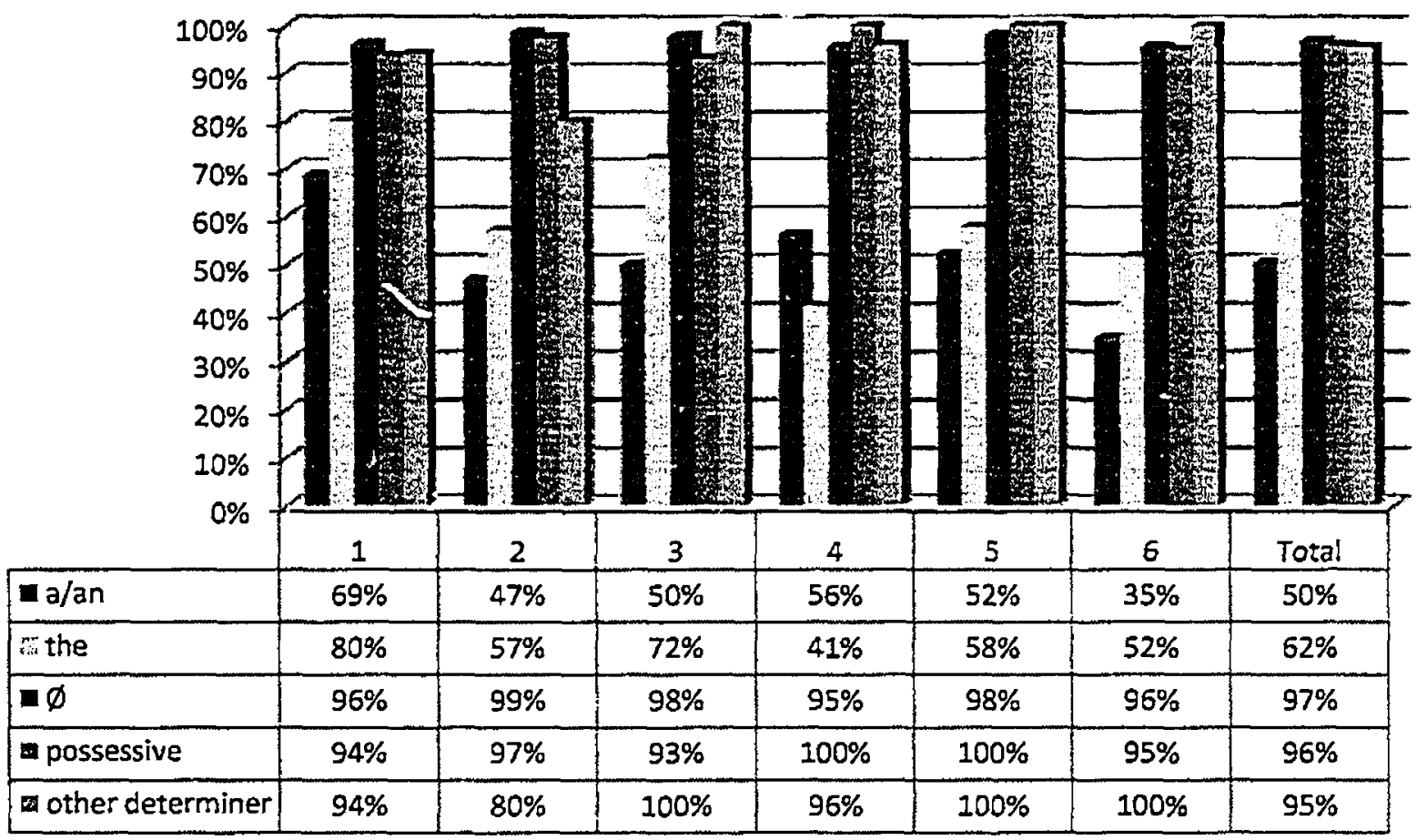

According to the figures described above, the overall level of accuracy of determiner use, as demonstrated by the journal entries of the students, was from most accurate to the least accurate: $\emptyset$, possessive, other determiner, the, and $a / a n$.

Analysis 2

The second analysis in this study identified, classified, and an alyzed the determiners used by the Japanese students according to the three groups of English determiners suggested by Master (1993) and Greenbaum and Quirk (1990): predeterminer, central determiner, and postdeterminer. Table 4-4 lists the English determiners in the two classifications proposed by Master (1993) and by Greenbaum and Quirk (1990). 
Table 4-4

Determ iner Classification

\begin{tabular}{|c|c|c|c|}
\hline & Predeterminer & Central Determiner & Posideterminer \\
\hline Master(1993) & $\begin{array}{l}\text { Quantifiers (e.g., all) } \\
\text { Muhtipliers (e.g., } \\
\text { both, double) } \\
\text { Fractions (e.g.. half. } \\
\text { two-thirds) } \\
\text { Inten sifiers (e.g., } \\
\text { what, such) }\end{array}$ & $\begin{array}{l}\text { Articies (a/an, the, } \emptyset \text { ) } \\
\text { Demonstratives (e.g., } \\
\text { this.those) } \\
\text { Possessives (e.g., } \\
\text { your. Mary's) } \\
\text { Assertive/ nonassertive } \\
\text { (e.g., some, any) } \\
\text { Negative (e.g., no) } \\
\text { Universal (e.g., each, } \\
\text { every) } \\
\text { Nonassertive dual } \\
\text { (e.g., either) } \\
\text { Negative dual (e.g., } \\
\text { neither) } \\
\text { Wh-determiners (e.g.. } \\
\text { which) }\end{array}$ & $\begin{array}{l}\text { Cardinal numerals } \\
\text { (e.g., one. three) } \\
\text { Ordinal numerals } \\
\text { (e.g., second) } \\
\text { General ordinals } \\
\text { (e.g., next) } \\
\text { Quantifiers (e.g., } \\
\text { many.few) }\end{array}$ \\
\hline $\begin{array}{l}\text { Greenbaum \& Quirk } \\
(1990)\end{array}$ & $\begin{array}{l}\text { all, both, half } \\
\text { Multipliers (e.g., } \\
\text { once, double) }\end{array}$ & $\begin{array}{l}\text { Same as Master's plus } \\
\text { Quantitative } \\
\text { determiner (e.g.. } \\
\text { enough) }\end{array}$ & $\begin{array}{l}\text { Ordinals (e.g.,first, } \\
\text { last.other) } \\
\text { Quantifiers (e.g., six, } \\
\text { twenty, many,few) }\end{array}$ \\
\hline
\end{tabular}

As Table 4-4 demonstrates, there are similarities and differences in the classifications presented by Master (1993) and Greenbaum and Quirk (1990). The three main classes of English determiners are the same: predeterminer, central determiner, and postdeterminer. However, recall that Master is more specific when classifying the determiners into their subcategories than are Greenbaum and Quirk. For instance, Master 
suggests four different subcategories for predeterminers and postdeterminers, while Greenbaum and Quirk present only two subcategories for these two classes of determiners. Central determiners are presented with the same subcategories by Master and Greenbaum and Quirk. However, in their grammar book, Greenbaum and Quirk add the subcategory quantitative determiner when referring to the central determiner enough. Although there are some differences in the subcategories of the English determiners proposed by Master and Greenbaum and Quirk, their general classification of determiners (predeterminer. central determiner, and postdeterminer) are essentially the same. Therefore, in th is analysis I will refer to Master's classification, as seen in Table 4-4. with the addition of enough as a central determiner.

Table 4.5

List of Different Types of Other Determ iners

\begin{tabular}{lll}
\hline Predeterminers & Central Determiners & Postdeterminers \\
\hline such & some & one, 20,3,4, four, 14, 10, \\
all & nough & twenty, 12,2, 15, 6, 13, \\
& this, that & first, next \\
& these, those & much, a lot of, few, many. \\
& every, each & more \\
& & another, other \\
\hline
\end{tabular}

In the first part of Analysis 2, I have reclassified the determiners (i.e., a/ an, the, $\emptyset$, possessive, and other determiner) according to the system proposed by Master (1993). Since the other determiner category included several different types of determiners, they were 
regrouped in to the predeterminer. central determiner and postdeterminer classifications. The occurrences of $a / a n$, the $\emptyset$, and possessives were then included as central determiners. Table 4-5 provides a list of the different types of other determiners used by the students according to Master's system (Table 4-5). Refer to Appendix B for a complete list of each student's use of the other determiners.

The results show that the total number of other determiners used by the six Japanese studen ts was 133 . Table 4-6 displays the numbers of occurrences of other determiners used by the Japanese students according to the three classes of English determiners: predeterminers, central determiners, and postdeterminers.

Table 4-6

Num ber of Occurrences for Other Determ iners

\begin{tabular}{lcccc}
\hline & Predeterminers & Central Determiners & Postdeterminers & Total \\
\hline Student 1 & 1 & 10 & 6 & 17 \\
Student 2 & 1 & 5 & 14 & 20 \\
Student 3 & 0 & 14 & 14 & 28 \\
Student 4 & 0 & 13 & 11 & 24 \\
Student 5 & 2 & 9 & 11 & 22 \\
Student 6 & 2 & 6 & 14 & 22 \\
Total & 6 & 57 & 70 & 133 \\
\hline
\end{tabular}

The count of other determiners revealed that postdeterminers had the highest number of occurrences. However, since the, $\varnothing, a / a n$, and possessives are included in the 
central determiner category, according to the English determiner descriptions of Master (1993), in the second part of Analysis 2, the occurrences of the articles and the possessives were also added to the total number of occurrences of central determiners. The final number of occurrences of central determ iners used by the participants totaled 1,168 . Since the count for postdeterminers was 70 and the number of instances of predeterminers was only 6 , it is safe to say that central determiners were by far the most used type of determiner found in the entries of the students' journals. These results make sense since Master (1993) suggests that central determiners make up the greatest group of determiners in English, and therefore they occur very frequently in this language. Table 4-7 demonstrates the number of occurrences of all the types of determiners used according to Master's classification system.

Table 4-7

Number of Occurrences According to English Determiner Classification

\begin{tabular}{lllll}
\hline & Predeterminers & Central Determiners & Postdeterminers & Total \\
\hline Student 1 & 1 & 186 & 6 & 193 \\
Student 2 & 1 & 171 & 14 & 186 \\
Student 3 & 0 & 246 & 14 & 260 \\
Student 4 & 0 & 156 & 11 & 167 \\
Student 5 & 2 & 138 & 11 & 151 \\
Student 6 & 2 & 271 & 14 & 287 \\
Total & 6 & 1,168 & 70 & 1,244 \\
\hline
\end{tabular}

Correctness of predeterminers, central determ iners, and posteterm iners used.

Once the data were grouped according to Master (1993), I in vestigated the occurrences and percentages of their correct use in the entries of the students' journals. To 
calculate the individual students' total control of the predeterminers, central determiners, and postdeterminers. I used the same formula employed in Analysis 1 (number of determiners used correctly divided by the total number of determiners used).

According to the results of Analysis 2 displayed in Figure 4-8 below, the total percentage of correct usage of the predeterminers reached $83 \%$. Postdeterm iners accounted for the highest percentage of correct usage $(91 \%)$. while the correct use of centra! determiners reached the lowest percentage of correct use. only $82 \%$. However, it is important to state that the difference in the number of accurrences among the three types of determiners was substantial: 6 occurrences of predeterminers. 70 occurrences of postdeterminers, and 1,168 occurrences of central determiners. Since central determiners had by far the largest number of occurrences, this type of determiner impacted the results significantly. Since central determiners $(1.168)$ accounted for the majority of all determiners $(1,244)$, it is not surprising that the total percentage correct of $82 \%$ reflected the percentage of correct central determiners $(82 \%)$.

Figure 4-5

Percentage Correct of Predeterminers, Central Determiners, and Postdeterminers

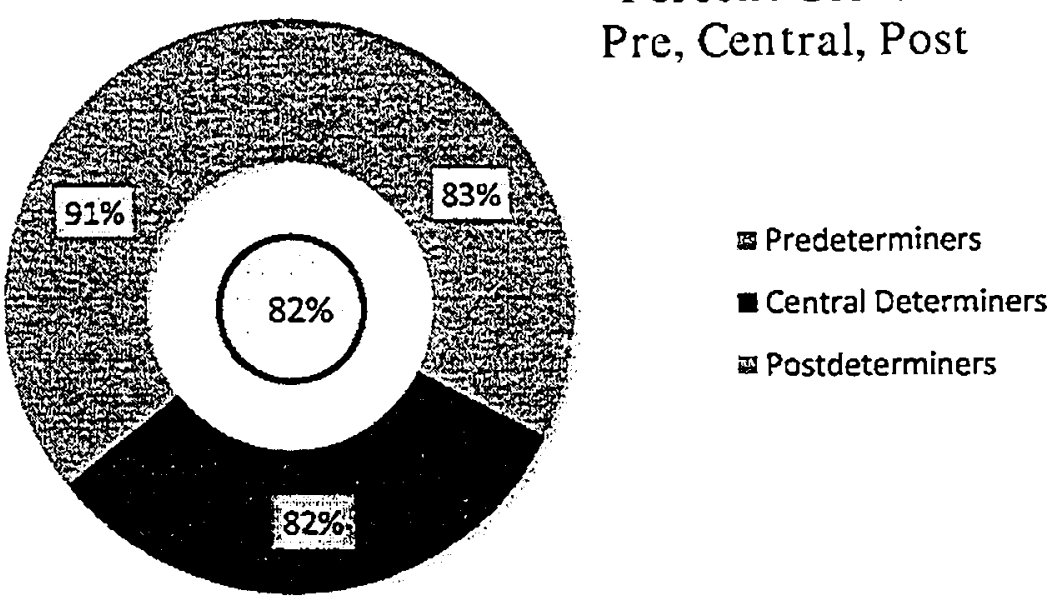

Percent Correct Pre, Central, Post Postdeterminers 


\section{Correct individual student usage of the determiners.}

The last part of Analysis 2 exam ined the correct individual student use for all three types of determ iners. Table 4-8 below displays the nu mber of determ iners used correctly (Yes) and incorrectly (No) by each individual student according to the determiner category (predeterminers, central detcrminers, and postdeterm iners). In addition. the table describes the total percentage of correct use as well as the in dividual student pereentage of accuracy of the predeterminers, central determiners, and postdeterminers used.

Table 4-8

Correct Determiner Usage

\begin{tabular}{|c|c|c|c|c|c|c|c|c|c|}
\hline \multirow{2}{*}{ Determiners } & \multirow{2}{*}{ Correct } & \multicolumn{6}{|c|}{ Student } & \multirow{2}{*}{ Total } & \multirow{2}{*}{$\%$ Correct } \\
\hline & & 1 & 2 & 3 & 4 & 5 & 6 & & \\
\hline \multirow{2}{*}{ Predeterminers } & No & 0 & 1 & 0 & 0 & 0 & 0 & 1 & \multirow{2}{*}{$83 \%$} \\
\hline & Yes & 1 & 0 & 0 & 0 & 2 & 2 & 5 & \\
\hline \multirow{2}{*}{$\begin{array}{l}\text { Central } \\
\text { Determiners }\end{array}$} & No & 22 & 31 & 39 & 27 & 29 & 68 & 216 & \multirow{2}{*}{$82 \%$} \\
\hline & Yes & 164 & 140 & 207 & 129 & 109 & 203 & 952 & \\
\hline \multirow{2}{*}{ Postdeterminers } & No & 1 & 4 & 0 & 1 & 0 & 0 & 6 & \multirow{2}{*}{$91 \%$} \\
\hline & Yes & 5 & 10 & 14 & 10 & 11 & 14 & 64 & \\
\hline \multirow{4}{*}{ Summary } & No & 23 & 35 & 39 & 28 & 29 & 68 & 222 & \multirow{4}{*}{$82 \%$} \\
\hline & Yes & 170 & 151 & 221 & 139 & 122 & 219 & 1022 & \\
\hline & Total & 193 & 186 & 260 & 167 & 151 & 287 & 1244 & \\
\hline & $\%$ Correct & $88 \%$ & $81 \%$ & $85 \%$ & $83 \%$ & $81 \%$ & $76 \%$ & $82 \%$ & \\
\hline
\end{tabular}

As seen in Table 4-8. the percentage correct ranged between $76 \%$ and $88 \%$ with 4 out of 6 students responding correctly between $81-85 \%$ of the time. Recall that Students 1, 2, and 3 had TOEFL scores of $500 / 173$ each: while Students 4, 5, and 6 had TOEFL scores of $520 / 190,550 / 213$, and 573/230; respectively. When we consider the percentage correct of the determiners used by the students with respect to their TOEFL scores, it is noticeable 
that Student 6. who had the highest TOEFL score (573/230), had the lowest accuracy fevel. $76 \%$, and Student 1, who had the lowest TOEFL score. (500/173) had the highest accuracy level. $88 \%$. In this case. assumptions that the more proficient the student, the more accurate their article choices (as in Butler. 2002) were not confirmed. However, the percentage correct is not the whole story of learners" delerminer use. as we see below. Analysis 3

The articles accounted for the majority of the determiner errors lound in the entries of the students journals (208 out of 222 instances of errors). In order to better understand the students misuse of the articles, their errors were categorized according to Mizuno"s (1985) classilications of types of errors in the use of the articles. In addition. the distribution of the errors committed by the students across the NP Types discussed in Huebner (1983). Thomas (1989). and Butler (2002) was also analyzed. This was done in order to determ inc the level of the students" inaccuracy related to the NP Types, as well as to try to understand why the students made the mistakes they made in the journal entries. Thus. Analysis 3 consisted of 2 parts: the lirst part in vestigated the types of crrors made by the Japanese students in their journal entries with regard to the articles. and the second part altempted to determine why they made such errors.

As discussed in Chapter 2. Mizuno (1985) examined the types ol errors in article use committed by $J$ apanese adult ESL learners in objective and productive tasks. He listed five lypes of errors com monly produced by adult $J$ apanese students during their interlanguage process. According to Mizuno. Japanese students are likely to com mit the following errors: Co-occurrence (the articles and other determiners are juxtaposed):

*A this book is on the floor.

Word-order (the order of the articles and the adjectives that follow them are inverted): 
*Marc has new a car.

Underextension (the articles are omitted):

"He is $\varnothing$ soccer player.

Overextension (the use of $a / a n$ or the instead of $\emptyset$ ):

*A whales are interesting animals.

Substitution (the use of the instead of $a / a n$ and vice versa):

*Mrs. Smith is a best teacher in the school.

Since most of the errors com milted by the Japanese students in this current study were errors related to the articles the (only $62 \%$ overall accuracy) and $a / a n$ (only $50 \%$ overall accuracy), Mizuno's liramework seemed appropriate to classify the errors com mitted by the Japanese students in the entries of their dialogue journals. In order to classify the types of errors committed by the students according to Mizunos (1995) system, all of the determ iner errors were listed per student, per entry. Afterwards. the errors were analyzed in terms of the types of errors suggested by Mizuno. However. only three types of errors from Mizuno's classifications (underextension, overextension, and substitution) were found in th is current data. Furthermore. since Mizuno only analyzed errors with the articies. other determ iner errors were classified as "other" (e.g.. errors related to the use of possessives and other determiners). Table 4-9 demonstrates the occurrences ol each student serrors per category. Refer to Appendix $C$ for a complete list of all the errors com mitted by the participants.

As tabie 4-9 illustrates, errors of underextension had the highest number of overall occurrences, 179 out ol 222 total instances of errors, or $81 \%$. In Mizuno: (1985) data. errors of underextension were also the most lirequent in the production task. and persisted across all proficiency levels. Errors of substitution and overextension persisted in the students' 
interlanguage process at the intermediale and advanced levels. These current data also show that even at the low-advanced level. students still comm it substitution and overextension errors. but to a limiled extent.

Table 4-9

Types of Errors per Student

\begin{tabular}{lrrrrrrrr}
\hline Error Types & \multicolumn{9}{c}{ Student } & \multicolumn{2}{c}{ Total } & $\%$ \\
\hline Undercxtension & 1 & 2 & 3 & 4 & 5 & 6 & $51 \%$ \\
Overextension & 14 & 28 & 28 & 24 & 28 & 57 & 179 & $5 \%$ \\
Substitution & 3 & 1 & 2 & 2 & 1 & 5 & 14 & $6 \%$ \\
Other & 4 & 5 & 6 & 1 & 0 & 4 & 20 & $9 \%$ \\
Total & 2 & 1 & 3 & 1 & 0 & 2 & 9 & $4 \%$ \\
\hline
\end{tabular}

Part 2 of Analysis 3 altempted to lind the reasons for the errors com milted by the Japanese students in their journal entries. In order to accomplish that. the distribution of the errors across the NP Types was also analyzed. The errors were classilied according to Hucbner`s (1983) and Bickerton 's (1981) NP Types (1-4) and Thomas" (1989) and Butler`s (2002) NP Type 5. Furthermore. a category was created lor the problems related to counrability als discussed in Yoon's study (1993).

Other problems, found in the journal entries, such as those related to the misuse of other determiners and possessives. were classified as "other". These errors were eliminated from this part of the analysis to focus solely on the articles and thus allow for a comparison with Mizuno's study. ${ }^{\text {The }}$ The distribution of the errors across the NP Types found in the

\footnotetext{
"There were six problems with other determiners. which were also cattegorized als errors of substitution, since lla students used ofher instead of anohher (NP Type 4). In addition, nine problems with possessives were lound. These errors did not lit the article error elassifications and were categorized als "other" (problems).
} 
Japanese students journal entries as seen below in Table 4-10 is also presented in Appendix D.

While analyzing the Japancse students errors, the following patterns of specific problems in the entries ol their journals emerged. A problem that seemed to be com mon across all entries of the J apanese students journals was the underextension of a/an. especially in Type 4 l-SR. -HK| contexts (69 occurrences. or 3S\%). For example: ..plecise tell me how to enjoy in foreign councry: and .. he is also undergraduate in Japan. The students also had a great number of problems regarding the underextension of the in Type 2 L+SR. +HKI contexts (57 occurrences. or $32 \%$ ). In these situations. the om ission of the seomed to be a lirequent error. especially in unique referent contexts such as. ...where was opened Wortd Cup the final round: and .. but the story of his and U.S.A. is so impressing. Besides that, instances of underextension of the in the idiomatic expression (Type 5) the same were lound. For example. The people were not same... and ...seem to be same with him. Takahashi (1997) lound that the choice of the delinite arlicle in common language use (idiomatic expressions) is more accurate than in ruk-governed use (non-common language use). This comparison is beyond the scope of this present study: however, it is worth mentioning that the current data show that students do not always rejy on common fanguage use to make their article choices. Table 4-11 displatys the nu mber of occurrences and the percentages of the underextension errors across the NP Types. 
Table 4-10

Distribution of Errors across NP Types

\begin{tabular}{lccccr}
\hline NP Type & Underextension & Overextension & Substitution & Total & Percentige \\
\hline $\begin{array}{l}\text { Type 1 } \\
\text { [-SR, +HK] }\end{array}$ & 30 & 6 & 0 & 36 & $17 \%$ \\
$\begin{array}{l}\text { Type 2 } \\
\text { [+SR. +HK] }\end{array}$ & 57 & 0 & 5 & 62 & $29 \%$ \\
$\begin{array}{l}\text { Type 3 } \\
\text { I+SR, -HK] }\end{array}$ & 14 & 0 & 4 & 18 & $9 \%$ \\
$\begin{array}{l}\text { Type 4 } \\
\text { [-SR, -HK! }\end{array}$ & 69 & 6 & 11 & 56 & $40 \%$ \\
$\begin{array}{l}\text { Type 5 } \\
\text { Idioms) }\end{array}$ & 4 & 1 & 0 & 5 & $2 \%$ \\
Countability & 5 & 1 & 0 & 6 & $3 \%$ \\
Total & 179 & 14 & 20 & 213 & $100 \%$ \\
\hline
\end{tabular}

Tiable 4-11

Number of Occurrences of Underestension Errors across NP Types

\begin{tabular}{|c|c|c|c|c|}
\hline NP Type & Occurrences & $\%$ & $\begin{array}{l}\text { Omission of } \\
\text { a/an }\end{array}$ & Omission of the \\
\hline $\begin{array}{l}\text { Type ! } \\
\text { |-SR. +HK! }\end{array}$ & 30 & $17 \%$ & 10 & 20 \\
\hline $\begin{array}{l}\text { Type } 2 \\
{[+\mathrm{SR} .+\mathrm{HK} \mid}\end{array}$ & 57 & $32 \%$ & 0 & 57 \\
\hline $\begin{array}{l}\text { Type } 3 \\
\text { |+SR. -HK| }\end{array}$ & 14 & 0 & 14 & 0 \\
\hline $\begin{array}{l}\text { Type } 4 \\
\text { [-SR. -HK] }\end{array}$ & 69 & $38 \%$ & 69 & 0 \\
\hline $\begin{array}{l}\text { Type } 5 \\
\text { (Idioms) }\end{array}$ & 4 & $2 \%$ & 0 & 4 \\
\hline Countability & 5 & $3 \%$ & 5 & 0 \\
\hline Total & 179 & $100 \%$ & $9 \mathrm{~S}$ & SI \\
\hline
\end{tabular}


The most common substitution error found in the Japanese students entries was the use of other instead of another ( 6 occurrences. or $30 \%$ ). Even though another is at postdeterminer (thus categorized as other determiner in the database) and not an article. this problem was also classitied as a substitution error. NP Type 4 (I-SR.-HK]): since another is an + other. For example. I don't like a person that change his or her attitude from one person to the other person. Errors of substitution with Type $21+\mathrm{SR} .+\mathrm{HK}$ and Type 4

[-SR.-HK] were the second most frequent among the substitution errors ( 5 occurrences, or 25\% each). Table $4-12$ below displays the occurrences and percentages of the substitution errors across the NP Types.

Table 4-12

Number of Occurrences of Substitution Errots across NP Types

\begin{tabular}{|c|c|c|c|c|c|}
\hline NP Type & Occurrences & $\%$ & $\begin{array}{r}a / a n \\
\text { instead of } \\
\text { the }\end{array}$ & $\begin{array}{r}\text { the } \\
\text { instead of } \\
\mathrm{a} / \mathrm{cm}\end{array}$ & $\begin{array}{r}\text { other } \\
\text { instead of } \\
\text { another }\end{array}$ \\
\hline $\begin{array}{l}\text { Type } 1 \\
{[-S R .+H K \mid}\end{array}$ & 0 & 0 & 0 & 0 & 0 \\
\hline $\begin{array}{l}\text { Type } 2 \\
\text { l+SR. +HKl }\end{array}$ & 5 & $25 \%$ & 5 & 0 & 0 \\
\hline $\begin{array}{l}\text { Type } 3 \\
\text { I+SR. - HKI }\end{array}$ & 4 & $20 \%$ & 0 & 4 & 0 \\
\hline $\begin{array}{l}\text { Typs } 4 \\
\text { |-SR. - HKI }\end{array}$ & 5 & $25 \%$ & 0 & 5 & 0 \\
\hline $\begin{array}{l}\text { Type } 5 \\
\text { (Idioms) }\end{array}$ & 0 & 0 & 0 & 0 & 0 \\
\hline Countability & 0 & 0 & 0 & 0 & 0 \\
\hline Other & 6 & $30 \%$ & 0 & 0 & 6 \\
\hline Total & 20 & $100 \%$ & 5 & 9 & 6 \\
\hline
\end{tabular}


Overextension errors in Type 4 l-SR. -HK! contexts with proper names were also produced. such as. On the New Years day... These types of errors accounted for $43 \%$ of the total overextension errors. Errors of overextension with Type [ [-SR. +HK]. such as.... because female friends are far more attentive in the others. also accounted for $43 \%$ of the total overextension errors, Overextension errors with Type 5 (Idioms) and countability each had one instance. or $7 \%$ each. Table $4-13$ illustrates the instances and percentages of al] overextension errors found in the current data.

Table $4-13$

Number of Occurrences of Overextension Errors across NP Types

\begin{tabular}{|c|c|c|c|c|}
\hline NP Type & Occurrences & $\%$ & $\begin{array}{r}\text { Overproduction } \\
\text { of the }\end{array}$ & $\begin{array}{r}\text { Overproduction } \\
\text { ol } a / a n\end{array}$ \\
\hline $\begin{array}{l}\text { Type } 1 \\
\text { |-SR.+HK| }\end{array}$ & 6 & $43 \%$ & 6 & 0 \\
\hline $\begin{array}{l}\text { Type } 2 \\
{[+\mathrm{SR}+\mathrm{HK} \mid}\end{array}$ & 0 & 0 & () & 0 \\
\hline $\begin{array}{l}\text { Type } 3 \\
\mid+ \text { SR. }-H K \mid\end{array}$ & 0 & 0 & 0 & 0 \\
\hline $\begin{array}{l}\text { Type } 4 \\
\text { [-SR. - HKl }\end{array}$ & 6 & $43 \%$ & 5 & 1 \\
\hline $\begin{array}{l}\text { Type } 5 \\
\text { (Idioms) }\end{array}$ & 1 & $7 \%$ & 1 & 0 \\
\hline Countability & 1 & $7 \%$ & 0 & 1 \\
\hline Total & 14 & $100 \%$ & 12 & 2 \\
\hline
\end{tabular}

Discussion

The discussion of the findings is presented below. First. the major findings of the study logether with a discussion of the causes of the students" errors are presented in 
relation to the findings of other studies. Then, the limitations of the current study are discussed.

One important finding in this study is that the order of accuracy with respect to article use in natural production from dialogue journals is $\emptyset$, the, and $a / a n$. This is significant because earlier studies (e.g., Yamada \& Matsuura, 1982 and Master 1987) produced conflicting results. Master (1987) reported that the order of accuracy for his [-Art] subjects was $\emptyset$, the, and $a / a n$ at the highest level of interlanguage. However, Yamada and Matsuura (1982) found that for their advanced level students, the accuracy order was the, $\emptyset$, and $a / a n$. The findings in this present study concur with those of Master (1987) with an accuracy order of $\emptyset$, the, and $a / a n$; but not with those of Yamada and Matsuura.

In addition, regarding the general accuracy level of the determiners, the results showed that $\emptyset$ was the most accurate with $97 \%$ accuracy. These results resemble the findings of Master (1987), in which, the accuracy of the $\emptyset$ article was close to $100 \%$ for his [-Art] speakers. However, the high rate of accuracy of the $\emptyset$ article may be questionable. given that, as Master explains, "since we cannot tell the difference between $\emptyset$ and non-use ur om ission of the article. acquisition is largely by default" (p. 2 16). Master (1987) further explains that acquisition of a/an occurred only after the was mastered. He suggested that "FArt l learners appear not to use a until they are sure it is correct and that getting it correct requires understanding and applying the notion of countability" (p. 218).

The next important result is the underextension of $a / a n$ and the as well as the low percentages of substitution and overextension errors. In Analysis 3, the students' errors were analyzed according to Mizuno's (1985) five categories of errors in article use, as well as the NP Types proposed by Huebner (1983) and Bickerton (1981) (Types 1-4), and Thomas(1989) and Butler (2002) (Type 5). This study contirmed Mizuno`s findings that 
underextension errors are more frequent than overextension errors in natural production data, and that errors of underextension, overextension, and substitution persist in the interlanguage process, even at the low-advanced level. The high rate of underextension errors found in these data $(81 \%)$ is interesting. Upon closer examination of the accuracy levels in combination with the error types, it seems clear that when these learners use the and $a / a n$, they use them fairly correctly with only $7 \%$ and $9 \%$ of the errors due to substitution or overextension. The low rates of overall accuracy for $a / a n(50 \%)$ and the $(62 \%)$ are probably due to their lack of use of the articles (i.e., underextension). It is worth noting that the results of Analysis 1 demonstrated that the $\emptyset$ article was the most accurate; however, it was only when the analysis of the errors was performed that it became clear that the students were actually overusing $\emptyset$. It is only by looking at the accuracy level in combination with the errors that one can understand how the students are actually using the article system. Thomas (1989) also found overgencralization of $\emptyset$ in $a /$ an and the contexts (underextension) to be the most common mistake in her data. She claimed that the overproduction of $\emptyset$ by her [-Art| students was caused by L1 transfer. This may also have been the reason for the Japanese students" underextension errors found in this present study, as discussed below.

Another important finding in this study is related to problems with $a / a n$ in Type 4 [$\mathrm{SR},-\mathrm{HK}]$ and the in Type $2[+\mathrm{SR},+\mathrm{HK}]$ contexts. As described earlier, Thomas (1989) compared the article acquisition of $\mathrm{LI}$ and $\mathrm{L} 2$ learners in natural production (a story-telling task). Her results demonstrate that L2 learners do not show early acquisition of $a /$ an in Type $4[-\mathrm{SR},-\mathrm{HK}]$ con texts and the in Type $2[+\mathrm{SR},+\mathrm{HK}]$ situations (unlike Ll learners). Since in the current data, problems with $a /$ an in Type 4 [-SR, - HK] and the in Type $2[+$ SR, 
$+\mathrm{HK} \mid$ situations accounted for the majority of the errors found in the entries of the students' journals, Thomas' findings were confirmed.

Finally, another major finding in th is current study was related to the lack of overproduction of the. This finding disagrees with Huebner's (1983). In his study, Huebner analyzed the use of da (the) in the speech of an adult $\mathrm{Hmong}$ speaker acquiring English in a natural setting. As mentioned before, at first, his subject overgeneralized the use of da (the) in all NP contexts. Later on, his subject maintained a high production of da (the) in Type 2 $[+\mathrm{SR},+\mathrm{HK}]$ and in Type $1[-\mathrm{SR},+\mathrm{HK}]$ contexts, but reduced the overproduction of the definite article in Type 4 [-SR, -HK] and Type $3[+\mathrm{SR},-\mathrm{HK}]$ situations. In general, my subjects had a low overproduction rate of the across all NP contexts (only 21 occurrences). It may be possible that the-flooding (as Huebner called it) is a phenomenon found in the first stages of article acquisition (beginner level). Since my subjects were considered lowadvanced ESL students, they may have been past this in itial article acquisition stage.

Now that we have seen the errors that these students have made, I turn to the following question: What is actually causing the errors? As mentioned above, errors of underextension, the most frequent on es, seem to be caused by L1 transfer (Thomas, 1989; Master, 1997). Master (1997) suggested that since articles are not present in [-Art| languages, [-Art $\mid$ speakers use (and misuse) the $\emptyset$ article very frequently in the first stages of the interlanguage, as well as in more advanced English proficiency levels. Master also suggested that in order to select the appropriate English article, L2 learners must take in to consideration certain notions such as countability, number, and definiteness. This can pose serious problems for L2 learners, especially the [-Art] speakers. Recall that Mizuno (1985) explained that in Japanese, in order to use a noun, it is not necessary to determine if the noun is countable or uncountable or if it is singular or plural. Consequently, $J$ apanese 
speakers have problems distinguishing count from non-count English nouns. Yoon (1993) also attributed countability problems to Ll transfer. She suggested that certain nouns that are uncountable in English may be equivalent to countable nouns in other languages and vice versa. Thus, in this case the language transfer would cause the Jearner to make the wrong article choice.

Although only a few instances of countability problems were found in the present data, it is important tot point out that most of these errors included the use of the predeterminer such. For example: "I hate such person." Hakuta (1976) discussed that due to the high frequency in which the articles occur in English and the fact that they are salient, learners usually retain these morphemes in their speech as pronunciation features of particular words or as a schwa. However, Hakuta explained that Brown (1973) suggested that "telling against their salience is the operation of liaison in English which causes articles to be frequently slurred and hard to tell apart, That's a becoming Thassa, and Pat the becoming Putta or Pudda" (p.338). In the entries of the J apanese students' journals, however, the omission of the article a/an may indicate that the students may think that the unstressed vowel sound ( $\operatorname{sch} w a$ ) is not spelled in English, and for that reason, they tend to commit the error of underextension of $a / a n$ when using the predeterminer such.

In general, the findings from this current study reveajed that even though only 222 occurrences of article-related errors (or $15 \%$ ) out of 1,425 instances of analyzed determiners were found, L1 transfer still plays a very significant role in the use (or non-use) of the articles by Japanese students, even at the low-advanced level. The fact that the articles are not present in Japanese poses a challenge to thess [-Art] ESL students when learning the English article system. The complexity of the use of the articles in English and the fact that 
they are absent in Japanese cause their accuracy to be lower than the accuracy of other determiners (e.g., postdeterminers) in natural language production.

To summarize briefly, I now return to the major findings of the study in relation to my research questions. One question focused on the level of accuracy of determiner use in dialogue journals. The accuracy orders found in this study with data from written discourse correspond to the accuracy orders found in Master's (1987) spoken discourse data. In addition, the question concerning learner errors not only revealed what types of errors learners made, but also helped to show that the accuracy order alone does not provide a complete picture of learner determiner use. Rather, onjy when the accuracy order is related to the analysis of learner errors, it is possible to understand learner production.

\section{Limitations}

Although these findings may be interesting, this current study presented some limitations that should be noted. First, the number of participants may have been too small to conduct a descriptive study that provided numerical results. Second, in the same manner, the small number of determiner occurrences may have affected the results. For example, in Analysis 2, the small number of occurrences of predeterminers and postdeterminers prevented a more precise accuracy level of determiner use. Also, while considered beyond the scope of this study, an analysis of the Noun Form category may have revealed additional information concerning the issue of countability and article choice. Finally, since studies such as Peyton (1986) and Dooley (1987) proved that students'use of some grammatical forms improve over time due to the practice of dialogue journals, a more longitudina! approach to in vestigate the use of the determiners may be more appropriate. 


\section{Chapter 5}

Conclusion

\section{Review of the Present Study and Findings}

The purpose of this research project was to describe the use of the English determiners in dialogue journals by Japanese L2 learners. As noted above, even though the articles and other determiners are words that occur very frequently in the English language. ESL learners are challenged by the complexity involved in the use of these determiners in Standard English. Master (1987) suggested that the acquisition of the articles depends on whether or not they are present in the learners' Ll. He further noted that students whose LI does not contain an article system (c.g., Japanese) will acquire the English articles more slowly than those students whose Ll does have articles (e.g., Spanish). A review of the literature confirmed that the L2 acquisition of articles in English by ESL students is a ffected by the Ll (e.g., Master, 1987), the type of language production required by the language task (e.g., Tarone \& Parrish, 1988; Mizuno, 1985), and the characteristics of the English determiner system (e.g.. Thomas, 1989; Yoon. 1993).

The review of the acquisition literature in combination with my own experiences with dialogue journals in the classroom led to the following research questions: How do Japanese students of ESL use the English article system. as well as other determ iners in natural written production, such as the entries of their dialogue journals? What is the level of accuracy of determ iner use? What types of errors do they make and why?

The findings revealed that these Japanese ESL learners demonstrate the following accuracy order for articles: $\emptyset$, the, and $a /$ an and the following order for the determiners: postdeterminers, predeterminers, and central determ iners. The results of the error analysis showed that these students are actually omitting the articles $a /$ an and the by overusing the 
article $\emptyset$; resulting in the low accuracy rates for the and $a /$ an. Furthermore, these learners' errors seem to be related to the concepts of NP Type 4 [-SR, -HKI and Type 2 [+ SR. +HK]. In general, what the results of th is study demonstrate regarding the use of the English articles by Japanese ESL students in dialogue journals is that errors are frequent and evident. even at the advanced level. Implications for the ESL Classroom

As seen in this study, because article errors persist for learners at the advanced level, it is appropriate to suggest that they be addressed in the classroom. First. students should be reminded of the rules pertaining to the use of the articles as well as other determiners. Master (1997) claimed that students at the advanced level may not have the desire to learn the gram matical rules of the English articles. He, however, su ggested that , -Art I speakers be taught the articles as "lexical items in context" (p, 227). After analyzing the use of the English determiners by Japanese students, I also suggest that the articles be taught and reinforced in the ESL classroom, even at the advanced level. Since LI transler seems to induce most of the errors related to English article use for these learners, teachers should be aware of how [-Art] students employ the article system, in order to help them minimize the problems. Given the results of this study, teachers should focus on the rules for a/an and the to encourage their increased use. Due to the errors evidence in this study, this would be especially important with NP Types $4[-\mathrm{SR},-\mathrm{HK}]$ and $2[+\mathrm{SR},+\mathrm{HK}]$.

In addition. since the use of the articles and other determiners depends on the type of noun they accompany, $I$ agree with Mizuno's (1985) suggestion, that new nouns be introduced as NPs that include possible article options such as: the $(\emptyset)$ summer. the (an) apple, $\emptyset$ Nashville. This study as well as my experiences with dialogue journals as a teach ing strategy, led me to believe that dialogue journals offer an appropriate lask in which to focus students' attention on the various NP contexts in a written discourse. After learning 
about the benelits of dialogue journals. I would defin itely use the journ als to teach the articles, since studies such as Peyton (1986) and Dooley (1987) found that accuracy of certain grammatical items improved over time. However, a more detailed and lon gitudinal study would have to be performed in order to confirm that.

\section{Recomm endations for Future Research}

More extensive research is recommended on the use of the articles, as well as other determiners in dialogue journals, sinee lew or no studies have been recently conducted in this area. In addition. based on the insightful arguments of Mizuno (1985) and Tarone and Parrish (1988) that diflerent tasks elicit different responses from students. it would be in formative to compare the accu racy level of the English determiners in dialogue journals with other types of tasks with natural language production as well as tasks with eliciled production, such as grammatical tests. Th is way, results of a more inclusive analysis could be described.

\section{Conclusion}

In conclusion, the results of this present study provided in formative in formation regarding the level of accuracy ri the articies by $\mathrm{J}$ apanese students in dialogue journals. When article accu racy is investigeted in these conditions, it is only by examin ing the accuracy of article used in combination with the types of errors committed by these students that we can understand how these |-Art | learners actually use the article system. It was surprising to see that the accuracy of the $\varnothing$ article found in Analysis I was called in to question when Analysis 3 (error analysis) was performed. 


\section{Works Ciled}

Bickerton. D. (1981). Roots of language. Ann Arbor, MI: Karoma.

Butler. Y. G. (2002). Second language learners theories on the use of English artieles: An analysis of the metalinguistic knowledge used by Japanese students in acquiring the English article system. Studies in Second Language Acquisition, 24. 45 I-4S0.

Dooley. M.S. (19S7). Dialogue journals: Facilitating the reading-writing connection with Native Am erican students. Unpublished requirement for a master"s degres. Northern Michigan Universily, Marquette.

Greenbaum. S.. \& Quirk. R. (1990). A student grammar of the English language. London: Longman.

Hakuta. K. (1976). A case study of a Japanese child learning English as a sccond language. Language Learning. 26. 321-351.

Hatch. E. M. (197S). Second language acquisition. A book of readings. Rowley. MA: Newbury House Publishers.

Holmes, V.. \& Moulton. M. (1997). Dialogue journals als an ESL learning strategy. Journal of Adolescent d Adult Literacy, 40.616-622.

Huebner. T. (1983). A longitudinal analysis of the acquisition of English. Ann Harbor. MI: Karomi.

Huebner. T. (19S5). System and variability in interlanguage syntax. Language Learning. 35. $141-163$.

Kreeti. J.E. (1984). Dialogue journal witing and the acquisition of grammatical morphology in English as a secend language. Unpublished doctoral dissertation. Georgetown University, Washington. D.C. 
Krecli. J.. Shuy. R.. Staton. J .. Reed. L.. \& Morroy. R. (19\$4). Dialogue witing: Analysis of student-leacher interactive writing in the learning of English as a second language (Final Report to the National Institute of Educalion. NIE-G-\$3-0030). Washington. DC: Center lor Applied Linguistics.

Lamb. H.. \&E Best. D. L. (1990). Language and literacy: The ESL whole language connection. (ERIC Document Reproduclion Service No. ED324915).

Loberger. G.. \& Welsh. K. S. (2002). Websteri new world English grammar handbook. Indianapolis. IN: Wiley Publishing.

Master. P. (1987). A cross-linguistic interlanguage andlysis of the acquisition of the English article system. Unpublished doctoral dissertation. Universily of California. Los Angeles.

Master. P. (1993. April). A contrastive study of determ iner usage in EST research aricles. Paper presented at the Teachers of English to Speakers of Other Languages (TESOL) Convention, Atlantal, Georgiat.

Master. P. (1997). The English article system: Acquisition, tunction. and pedagogy. System. $25.215-232$.

Mizuno, H. (19S5). A psycholinguistic approach to the article system in English. JACET Bulletin. 16. 1-29.

Peyton. J. K. (19S6). Dialogue journal writing and the acquisition of English grammatical morphology. Center for Applied Linguistics. Wash ington. D.C. (ERIC Document Reproduction Service No. ED276257).

Peyton. J. (1997). Dialogue journals: Interactive wrising to develop language and literacy. Energency Librarian. 24. 46-49.

Staton. J. (19S7). Dialogue joumals. ERIC Digust. Bloomington. IN: ERIC Clearinghousc on Reading. English. and Communication. 
Staton. J .. Shuy. R.. Kreclt. J .. dE Red. L. (19SS). Dialogue journat com munication: Classroom. Iinguistic. social, and cognitive views. Norwood. N.J .: Ablex.

Takahashi. T. (1997). J apanese learners"acquisition and use of the English article system. Edinbursh Workins Papers in Applied Linguisrics. \$. 9\$-110.

Tarone. E.. \& Parrish. B. (198S). Talsk-related variation in interlanguage: The case of articles. Language Leaming. 38.2 [-43.

Thomas. M. (1989). The acquisition of English articles by first-and sceonci-language learners. Applied Psycholinguistics. 10. 335-355.

Yamada. J.. \& Matsuura. N. (1982). Th心 usc of the English articles among J apanese students. RELCJournal. $13,50-63$.

Yoon. K. K. (1993). Challenging prototype descriptions: Perceptions ol noun countability and indelïnite vs. zero article use. IRAL. 31.269-289. 


\section{APPENIDIX A}

Questionnalire

1- What is your name?

2- Gender: ( ) male ( ) female

3- How old are you?

4- What is your country of birth?

5- What is your native langualge?

6- How long have you been studying English?

7- How long have you been in the United States?

S- What is your most recent TOEFL score?

9- What is your English placenent lest score?

10- Where have you studied English before coming here?

11- Why clid you decide to study in a college in the United States?

12- What is your inajor?

13- What is/are your falvorite skill area(s) of English ats a Second Language (ESL)? Why?

14- What skill area(s) ol ESL do you think is/are casier for you to laan? Why?

15- Whalt skill area(s) of ESL do you think is/are more difficult for you to learn? Why?

16- What are some of the strategies you use to improve your reading skills?

17- What are some of the strategies you use to improve your listen ing skills?

IS - What are some of the st ralegies you use to improve your speaking skills?

19- What are some of the strategies you use to improve your grammar skils?

20)- What are some of the strategies you use to improve your writing skills? 


\section{APPENDIX B}

Complete list of items in the other determiner category

\section{Surdent I}

Entry!

one person - postdeterminer (cardinal numeral)

the other person - postdeterminer (general ordinal)

some help - eentral determiner (general assertive)

\section{Entry 2}

13 years old - postdelerniner (cardinal numeral)

1,3 years old-postdeterminer (cardinal numeral)

no idea - central delerminer (negitive)

Entry 3

no sense- central determiner (negative)

Entry 4

no ide:a-central determiner (negative)

Entry 5

these things - eentral determiner (demonstrative)

\section{Entry 6}

This Japanese club trip-central determiner (demonstrative)

Entry 7

every yealr - central determiner (universal)

miny different kinds - postdetermnier (quantifier)

All Japanese - predeterminer (quamilier)

everv family member - centril determiner (universal)

this semester - eentral determiner (demonstrative)

one of the most - postdeterminer (cirdinal numeral)

Entry $\$$

This dialogue joumal - central determiner (demonstrative)

\section{Studen 2}




\section{Entry 1}

3 real friends - posideterminer (cardinal numeral)

two of them - postdeterminer (cardinal numeral)

Ëach other - central determiner (universial)

ailiel country - postdeterminer (general ordinal)

\section{Entry 2}

other country - posideierminer (general ordinil)

not every Americam is bad - central detemniner (universil)

\section{Entry 3}

20) mins. - postdeterminer (cardinal numeral)

in other city - postdeterminer (general ordinal)

each other- eentral determiner (universal)

\section{Entry 4}

to other college - postdeterminer (general ordinal)

al few years - postdeterminer (quantilier)

\section{Entry 5}

a lot ol things - postdelerminer (quantiliter)

a lot of things - postdeterminer (quantificr)

Entry 6

4 days - postdeterminer (cardinal numeral)

that hotel - central determiner (demonstrative)

If hours - postdeterminer (cardinal numeral)

\section{Entry 7}

a lot ol people - postdeterminer (quatntifier)

Most people - predeterminer (quantifïr)

this time-central determiner (demonstrative)

a lot of people - postdeterminer (quantitier)

Entry $S$

No occurrences of other determiners

\section{Sruden 3}

\section{Entry 1}

Eich other - central determiner (universil)

twenty years - postdeterminer (cirdinal numeral) 
each individual way other - central determiner (universal)

each other - central determiner (universal)

Entry 2

much time - postdeterminer (quantifiar)

each opinion other - central determiner (universal)

each other-central determiner (universal)

each other-central determiner (universal)

\section{Entry 3}

much snow - postdeterminer (quantifier)

that time - central determiner (demonstrative)

this year - central determiner (demonstrative)

two years - postdeterminer (cardinal numeral)

some big competitions - central determiner (assertive)

2 years - postdeterminer (cardinal numeral)

6 years- postdeterminer (cardinal numeral)

Entry 4

some of - central determiners (assertive)

Entry 5

a lot of friends - postdeterminer (quantifier)

these days - central determiner (demonstrative)

\section{Entry 6}

1 day - postdeterminer (cardinal numeral)

a few strange and exotic things - postdeterminer (quantifier)

some objections - central determiner (assertive)

a lot of people - postdeterminer (quantifier)

\section{Entry 7}

another problem - postdeterminer (general ordinal)

this coilege life - central determiner (demonstrative)

one of the problems - postdeterminer (cardinal numeral)

\section{Entry $S$}

this type - central determiner (demonstrative)

more controversial themes - postdeterminer (quantifier)

next year - postdeterminer (general ordinal) 


\section{Student 4}

\section{Entry I}

this question - central determiner (demonstrative)

one of my best friends - postdeterminer (cardinal numeral)

each other - central determiner (universal)

one thing- postdeterminer (cardinal number)

\section{Entry 2}

many friends - postdeterminer (quantifier)

lived other country - postdeterminer (general ordinal)

each_other - central determiner (universal)

\section{Entry 3}

5.people - postdeterminer (cardinal numerai)

some entertainment park - central determiner (assertive)

some way- central determiner (assertive)

some pets- central determiner (assertive)

two very important family members - postdeterminer (cardinal numeral)

Entry 4

manv languages - postdeterminer (quantifier)

many countries - postdeterminer (quantifier)

Entry 5

many things - postdeterminer (quantifier)

some special advice - central determiner (assertive)

\section{Entry 6}

this Thanksgiving break-central deteminer (demonstrative)

il lot of things - postdeterminer (quantifier)

this trip - central determiner (demonstrative)

\section{Entry 7}

ench meal - central determiner (universal)

\section{Entry $S$}

each other - central determiner (universal)

each other - central determiner (universal)

some compositions - central determiner (assertive)

one more thing - postdeterminer (cardinal numeral) 
Studeni 5

Entry 1

this assignment - central determiner (demonstrative)

almost all Japanese students - predeterminer (quantifier)

this disadvantage - central determiner (demonstrative)

this class - central determiner (demonstrative)

stich elements - predeterminer (intensifier)

\section{Entry 2}

another country - postdeterminer (general ordinal)

another country-postdeterminer (general ordinal)

another country- postdeterminer (general ordinal)

Entry 3

these days - central determiner (demonstrative)

one of the reasons - postdeterminer (cardinal numeral)

Entry 4

enough money - central determiner (quantitative)

first step - postdeterminer (general ordinal)

\section{Entry 5}

No occurrences of other determiners:

\section{Entry 6}

few days - postdeterminer (quantifier)

more energy - central determiner (quantitative)

$50^{\circ}$ clock - postdeterminer (cardinal numeral)

\section{Entry 7}

three practices - postdeterminer (cardinal numeral)

each practice - central determiner (universal)

two hours - postdeterminer (cardinal numeral)

four months - postdeterminer (cardinal numeral)

\section{Entry $S$}


This assignment - central determiner (demonstrative)

10 or 12 times - postdeterminer (cardinal numeral)

this chance - central determiner (demonstrative)

\section{Studen 6}

\section{Entry 1}

No occurrences of other determiners

\section{Entry 2}

other cultures - postdeterminer (general ordinal)

\section{Entry 3}

4 brothers - postdeterminer (cardinai numeral)

more guts - central determiner (quantifier)

three sisters - postdeterminer (cardinal numral)

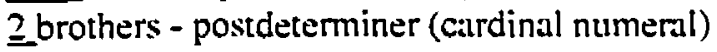

1 sister - postdeterminer (cardinal numeral)

four vears - postdeterminer (cardinal numeral)

one or two passengers - postdeterminer (cardinal numeral)

two years - postdeterminer (cardinal numral)

no brothers - central determiner (negative)

one of the best universities - postdeterminer (cardinal numeral)

Entry 4

No occurrences of other determiners

\section{Entry 5}

three days - postdeterminer (cardinal numeral)

Those buildings - central determiner (demonstrative)

15 hours - postdeterminer (cardinal numeral)

\section{Entry 6}

two groups - postdeterminer (cardinal numeral)

One group - postdeterminer (cardinal numeral)

more Japanese - central determiner (quantitiative)

\section{Entry 7}

two picces - postdeterminer (cardinal numeral)

Most Japanese - predeterminer (quantitier)

These New Year visits - central determiner (demonstrative)

mostcases - predetermier (quantifter) 


\section{Entry 8}

This journal - central determiner (demonstrative) 


\section{APPENDIXC}

Error Analysis

Student 1

Entry 1

\begin{tabular}{|l|l|l|l|}
\hline NP & NP & Context for & Type of Error \\
\hline 10 & the other person & $\begin{array}{l}\text { other det. - I } \\
\text { (another person) }\end{array}$ & substitution \\
\hline
\end{tabular}

Entry 2

\begin{tabular}{|l|l|l|l|}
\hline NP\# & NP & Context for & Type of Error \\
\hline 6 & conversation s class & P-I & other (problem) \\
\hline 25 & in foreign country & a/an $-I$ & underextension \\
\hline 9 & most of the Japanese & $\varnothing-I$ & overextension \\
\hline
\end{tabular}

Entry 3

\begin{tabular}{|l|l|l|l|}
\hline NP\# & NP & Context for & Type of Error \\
\hline 5 & $\begin{array}{l}\text { he is also } \\
\text { undergraduate }\end{array}$ & alan - I & underextension \\
\hline 10 & a computer trouble & $\emptyset-I$ & countability \\
\hline 24 & to be same & the $-I$ & underextension \\
\hline 26 & hard worker & $\mathrm{a} / \mathrm{a}-\mathrm{I}$ & underexension \\
\hline 32 & Aquarium & the-I & underextension \\
\hline 33 & a civic ha!l & the $-I$ & substitution \\
\hline 36 & samequestions & the $-I$ & underextension \\
\hline
\end{tabular}

Entry 4

\begin{tabular}{|l|l|l|l|}
\hline NP\# & NP & Context for & Type of Error \\
\hline$S$ & the job & a/an $-I$ & substitution \\
\hline 9 & the TV station & a/an- I & substitution \\
\hline
\end{tabular}

\section{Entry 5}

\begin{tabular}{|l|l|l|l|}
\hline NP\# & NP & Context for & Type of Error \\
\hline 4 & or important person & $\mathrm{a} / \mathrm{an}-\mathrm{I}$ & underextension \\
\hline
\end{tabular}


Entry 6

\begin{tabular}{|l|l|l|l|}
\hline NP\# & NP & Context for & Type of Error \\
\hline 24 & wonderful trip & a/ann-1 & underextension \\
\hline
\end{tabular}

\section{Entry 7}

\begin{tabular}{|l|l|l|l|}
\hline NP\# & NP & Context for & Type of Error \\
\hline 5 & of year & the- I & undersextension \\
\hline 11 & kind of noodle & a/an-I & underextension \\
\hline 15 & going to shrine & a/an-I & underextension \\
\hline 17 & $\begin{array}{l}\text { On the New Years } \\
\text { day }\end{array}$ & $\emptyset-I$ & overextension \\
\hline 20 & Festive food & a/an-I & countability \\
\hline 43 & that name (its name) & P-I & other (problem) \\
\hline
\end{tabular}

\section{Entry $S$}

\begin{tabular}{|l|l|l|l|}
\hline NP\# & NP & Context for & Type of Error \\
\hline 6 & dialogue journal & the - I & underextension \\
\hline S & for dialogue journal & the- & underextension \\
\hline
\end{tabular}

Student 2

\section{Entry 1}

\begin{tabular}{|l|l|l|l|}
\hline NP\# & NP & Context for & Type of Error \\
\hline 8 & same university & the - I & underextension \\
\hline 16 & not parent's & a/an & underextension \\
\hline 23 & such as the problem & i/ an $-I$ & substitution \\
\hline 24 & or future & the - I & underextension \\
\hline 26 & the time & $\emptyset-I$ & overextension \\
\hline 38 & because of culture & the - I & underextension \\
\hline 43 & $\begin{array}{l}\text { other country } \\
\text { (another country) }\end{array}$ & other det.- I & substitution \\
\hline
\end{tabular}




\section{Entry 2}

\begin{tabular}{|l|l|l|l|}
\hline NP\# & NP & Context for & Type of Error \\
\hline 3 & real friend & a/an-I & underextension \\
\hline 4 & $\begin{array}{l}\text { other country } \\
\text { (another country) }\end{array}$ & other det.- I & substitution \\
\hline 7 & SSA people & the $-I$ & underextension \\
\hline 10 & $\begin{array}{l}\text { have international } \\
\text { boyfriend }\end{array}$ & a/an $-I$ & underextension \\
\hline 13 & who is good guy & $\mathrm{a} / \mathrm{an}-\mathrm{I}$ & underextension \\
\hline
\end{tabular}

Entry 3

\begin{tabular}{|l|l|l|l|}
\hline NP\# & NP & Context for & Type of Error \\
\hline 15 & $\begin{array}{l}\text { in other city (in } \\
\text { another city) }\end{array}$ & other det. I & substitution \\
\hline 17 & He is en sincer & a/an $-I$ & underextension \\
\hline 19 & is public servant & a/an $-I$ & underextension \\
\hline 22 & World Cup & the-I & underextension \\
\hline 25 & only child & a/an-I & underextension \\
\hline 28 & $\begin{array}{l}\text { to parents (to my } \\
\text { parents) }\end{array}$ & P-I & other (problem) \\
\hline 32 & strong relationship & a/an I & underextension \\
\hline 36 & opposite situation & the I & underextension \\
\hline 37 & serious problem & a/an-I & underextension \\
\hline
\end{tabular}

\section{Entry 4}

\begin{tabular}{|l|l|l|l|}
\hline NP\# & NP & Context for & Type of Error \\
\hline 3 & try internship & a/an-I & underextension \\
\hline 7 & more specific field & a/an-I & underextension \\
\hline 12 & $\begin{array}{l}\text { to other college } \\
\text { (another college) }\end{array}$ & other det. - I & substitution \\
\hline 14 & only child & a/an-I & underextension \\
\hline
\end{tabular}

\section{Entry 5}

\begin{tabular}{|l|l|l|l|}
\hline NP\# & NP & Context for & Type of Error \\
\hline 8 & news & the-I & underextension \\
\hline 10 & developing country & a/ an $-I$ & underextension \\
\hline
\end{tabular}


Entry 6

\begin{tabular}{|l|l|l|l|}
\hline NP\# & NP & Context for & Type of Error \\
\hline 5 & First & the-I & underextension \\
\hline 7 & and hotel & the-I & underextension \\
\hline 16 & spend nice time & a/an-I & underextension \\
\hline 18 & wrongway & the-I & underextension \\
\hline 23 & $\begin{array}{l}\text { during winter } \\
\text { vacation }\end{array}$ & the-I & underextension \\
\hline
\end{tabular}

\section{Entry 7}

\begin{tabular}{|l|l|l|l|}
\hline NP\# & NP & Context for & Type of Error \\
\hline 3 & to temple & $\mathrm{a} / \mathrm{an}-\mathrm{I}$ & underextension \\
\hline 4 & to shrine & $\mathrm{a} / \mathrm{a}$-I & underextension \\
\hline 6 & of year & the-I & underextension \\
\hline
\end{tabular}

Entry 8

No errors found.

Student 3

Entry 1

No errors found.

Entry 2

\begin{tabular}{|l|l|l|l|}
\hline NP\# & NP & Context for & Type of Error \\
\hline 13 & A style & the-I & substitution \\
\hline 19 & $\begin{array}{l}\text { respect } \\
\text { individualism }\end{array}$ & the-I & underextension \\
\hline 39 & $\begin{array}{l}\text { write those board } \\
\text { (write on the board) }\end{array}$ & the-I & substitution \\
\hline 44 & have variety & a/an-I & underextension \\
\hline
\end{tabular}

Entry 3

\begin{tabular}{|l|l|l|l|}
\hline NP\# & NP & Context for & Type of Error \\
\hline 1 & I have father & a/an $-I$ & underextension \\
\hline 2 & mother & $a / a n-I$ & underextension \\
\hline 3 & and old brother & a/an $-I$ & underextension \\
\hline 5 & for company & a/an $-I$ & underextension \\
\hline
\end{tabular}




\begin{tabular}{|l|l|l|l|}
\hline 9 & $\begin{array}{l}\text { in the Nigata } \\
\text { prefecture }\end{array}$ & $\varnothing-I$ & overextension \\
\hline 14 & of neighborhood & the-I & underextension \\
\hline 20 & the university & a/an-I & substitution \\
\hline 27 & at university & the-I & underextension \\
\hline
\end{tabular}

\section{Entry 4}

\begin{tabular}{|c|c|c|c|}
\hline NP\# & NP & Context for & Type of Error \\
\hline 4 & the occupation & $\mathrm{a} / \mathrm{an}-\mathrm{I}$ & substitution \\
\hline 7 & United Nations & the-I & underextension \\
\hline 14 & The style & $\varnothing-I$ & overextension \\
\hline 17 & the person & $a / a n-I$ & substitution \\
\hline 18 & person & the-I & underextension \\
\hline 23 & for variety & $a / a n-I$ & underextension \\
\hline 26 & $\begin{array}{l}\text { most important } \\
\text { thing }\end{array}$ & the-I & underextension \\
\hline
\end{tabular}

\section{Entry 5}

\begin{tabular}{|l|l|l|l|}
\hline NP\# & NP & Context for & Type of Error \\
\hline 1 & $\begin{array}{l}\text { With lover (with my } \\
\text { lover) }\end{array}$ & P-I & other \\
\hline 4 & It's good time & a/an-I & underextension \\
\hline 21 & It's good time & $\mathrm{a} / \mathrm{an}-\mathrm{I}$ & underextension \\
\hline 24 & new knowledge & $\mathrm{a} / \mathrm{a} n-I$ & underextension \\
\hline 39 & $\begin{array}{l}\text { The laziness (my } \\
\text { laziness) }\end{array}$ & P-I & substitution \\
\hline
\end{tabular}

\section{Entry 6}

\begin{tabular}{|l|l|l|l|}
\hline NP\# & NP & Context for & Type of Error \\
\hline $\mathbf{2}$ & a J apanese club & the-I & substitution \\
\hline 16 & not same & the-I & underextension \\
\hline 34 & and U.S.A. & the-I & underextension \\
\hline
\end{tabular}

\section{Entry 7}

\begin{tabular}{|l|l|l|l|}
\hline NP\# & NP & Context for & Type of Error \\
\hline 4 & nice place & a/an-I & underextension \\
\hline 6 & by kindness & the-I & underextension \\
\hline 14 & $\begin{array}{l}\text { as groups (as a } \\
\text { group) }\end{array}$ & a/an-I & underextension \\
\hline 22 & have connection & a/an-I & underextension \\
\hline 23 & with outside & the-I & underextension \\
\hline
\end{tabular}




\begin{tabular}{|l|l|l|l|}
\hline 27 & like city & the-I & underextension \\
\hline 28 & good place & a/an-I & underextension \\
\hline 29 & $\begin{array}{l}\text { experience } \\
\text { "differency" (the } \\
\text { difference) }\end{array}$ & the-I & underextension \\
\hline 30 & and diversity & the-I & underextension \\
\hline
\end{tabular}

\section{Entry 8}

\begin{tabular}{|l|l|l|l|}
\hline NP\# & NP & Context for & Type of Error \\
\hline 9 & $\begin{array}{l}\text { improve English } \\
\text { ability (improve } m y \\
\text { English ability) }\end{array}$ & P-I & other \\
\hline 20 & explanation & the-I & underexentesion \\
\hline 25 & difference & the-I & underexentesion \\
\hline
\end{tabular}

\section{Student 4}

\section{Entry 1}

\begin{tabular}{|l|l|l|l|}
\hline NP\# & NP & Con text for & Type of Error \\
\hline 11 & about problem & a/an $-I$ & underextension \\
\hline 16 & serious issue & a/an $-I$ & underextension \\
\hline 22 & long time & a/an $-I$ & underextension \\
\hline 25 & real friend & a/an $-I$ & underextension \\
\hline
\end{tabular}

\section{Entry 2}

\begin{tabular}{|l|l|l|l|}
\hline NP\# & NP & Context for & Type of Error \\
\hline 2 & $\begin{array}{l}\text { anyone who is my } \\
\text { special }\end{array}$ & $\emptyset-I$ & overextension \\
\hline 13 & $\begin{array}{l}\text { lived other country } \\
\text { (lived in another } \\
\text { country) }\end{array}$ & other. det-I & substitution \\
\hline 15 & short time & a/an-I & underxtension \\
\hline
\end{tabular}

\section{Entry 3}

\begin{tabular}{|l|l|l|l|}
\hline NP\# & NP & Context for & Type of Error \\
\hline 7 & to movie & a/ an $-\mathrm{I}$ & underextension \\
\hline 11 & children & the-I & underextension \\
\hline 18 & unusual thing & a/an-I & underextension \\
\hline 26 & only person & the-I & underextension \\
\hline 30 & $\begin{array}{l}\text { very different } \\
\text { personality }\end{array}$ & a/an-I & underextension \\
\hline
\end{tabular}


Entry 4

\begin{tabular}{|l|l|l|l|}
\hline NP\# & NP & Context for & Type of Error \\
\hline 11 & in countryside & the-I & underextension \\
\hline 12 & without car & $a / a n-I$ & underextension \\
\hline 14 & $\begin{array}{l}\text { get D.L. (driver's } \\
\text { license) }\end{array}$ & $a / a n-I$ & underextension \\
\hline
\end{tabular}

\section{Entry 5}

\begin{tabular}{|l|l|l|l|}
\hline NP\# & NP & Con text for & Type of Error \\
\hline 2 & most happy time & the-I & underextension \\
\hline
\end{tabular}

Entry 6

\begin{tabular}{|l|l|l|l|}
\hline NP\# & NP & Context for & Type of Error \\
\hline 19 & "parad" (parade) & the-I & underextension \\
\hline 20 & the Thanksgiving day & $\varnothing-I$ & overextension \\
\hline 22 & hotel & the-I & underextension \\
\hline 23 & hotel's lounge & the-I & underextension \\
\hline 29 & duringwinter break & the-I & underextension \\
\hline 31 & during break & the-I & underextension \\
\hline
\end{tabular}

Entry 7

\begin{tabular}{|l|l|l|l|}
\hline NP\# & NP & Context for & Type of Error \\
\hline 3 & New Year & the-I & uderextension \\
\hline 5 & shrine & $a / a n-I$ & underextension \\
\hline 6 & whole year & $a / a n-I$ & underextension \\
\hline 8 & really big dinners & $a / a n-I$ & underextension \\
\hline 10 & meaning & $a / a n-I$ & underextension \\
\hline 12 & on the New Year's & $\emptyset-I$ & overextension \\
\hline
\end{tabular}

Entry 8

No errors found.

Student 5

\section{Entry I}

\begin{tabular}{|l|l|l|l|}
\hline NP\# & NP & Context for & Type of Error \\
\hline 8 & be help & a/an-I & underextension \\
\hline
\end{tabular}




\begin{tabular}{|l|l|l|l|}
\hline 23 & appreciate friend & a/an $-\mathrm{I}$ & underextension \\
\hline 24 & treat friend & $\mathrm{a} / \mathrm{an}-\mathrm{I}$ & underextension \\
\hline 27 & such personality & $\mathrm{a} / \mathrm{an}-\mathrm{I}$ & countability \\
\hline 33 & opposite way & $\mathrm{a} / \mathrm{an}-\mathrm{I}$ & underextension \\
\hline
\end{tabular}

\section{Entry 2}

\begin{tabular}{|l|l|l|l|}
\hline NP\# & NP & Context for & Type of Error \\
\hline 4 & such friend & a/an $-I$ & countability \\
\hline 18 & such person & $\mathrm{a} / \mathrm{an}-\mathrm{I}$ & countability \\
\hline 23 & way & $\mathrm{a} / \mathrm{an}-\mathrm{I}$ & underextension \\
\hline
\end{tabular}

Entry 3

\begin{tabular}{|l|l|l|l|}
\hline NP\# & NP & Context for & Type of Error \\
\hline 8 & such situation & $\mathrm{a} /$ an $-I$ & Countability \\
\hline
\end{tabular}

Entry 4

\begin{tabular}{|l|l|l|l|}
\hline NP\# & NP & Context for & Type of Error \\
\hline 5 & past & the-I & underextension \\
\hline 11 & great reputation & a/an $-I$ & underextension \\
\hline 17 & of stair & the-I & underextension \\
\hline 18 & to small goal & a/an $-I$ & underxtension \\
\hline 20 & to be cool gentieman & $a / a n-I$ & underextension \\
\hline
\end{tabular}

\section{Entry 5}

\begin{tabular}{|l|l|l|l|}
\hline NP\# & NP & Context for & Type of Error \\
\hline 5 & from view & the-I & underextension \\
\hline 6 & on face & the-I & underextension \\
\hline 7 & as bright smile & a/an $-I$ & underextension \\
\hline
\end{tabular}

\section{Entry 6}

\begin{tabular}{|l|l|l|l|}
\hline NP\# & NP & Context for & Type of Error \\
\hline 7 & energetic person & $\mathrm{a} / \mathrm{an}-\mathrm{I}$ & underextension \\
\hline 11 & At the midnight & $\emptyset-\mathrm{I}$ & overextension \\
\hline 14 & traffic jam & $\mathrm{a} / \mathrm{an}-\mathrm{I}$ & underextension \\
\hline 22 & barber & $\mathrm{a} / \mathrm{an}-\mathrm{I}$ & underextension \\
\hline 23 & Japanese bar & $\mathrm{a} / \mathrm{an}-\mathrm{I}$ & underextension \\
\hline 24 & jazz bar & $\mathrm{a} / \mathrm{a} n-\mathrm{I}$ & underextension \\
\hline
\end{tabular}


Entry 7

\begin{tabular}{|l|l|l|l|}
\hline NP\# & NP & Context for & Type of Error \\
\hline 7 & $3\left(3^{\text {rd }}\right)$ & the-I & underextension \\
\hline 15 & winter break & the-I & underextension \\
\hline 17 & be nice break & a/an-I & underextension \\
\hline
\end{tabular}

\section{Entry 8}

\begin{tabular}{|l|l|l|l|}
\hline NP\# & NP & Context for & Type of Error \\
\hline 6 & improve skill & the-I & underextension \\
\hline 9 & turning point & $\mathrm{a} / \mathrm{an}$ & underextension \\
\hline 14 & in ESL class & the-I & underextension \\
\hline
\end{tabular}

Student 6

\section{Entry 1}

\begin{tabular}{|c|c|c|c|}
\hline NP\# & $\mathrm{NP}$ & Context for & Type of Error \\
\hline 17 & to the others & $\varnothing-I$ & overextension \\
\hline 25 & $\begin{array}{l}\text { about "careness" } \\
\text { (care) }\end{array}$ & the-I & underextension \\
\hline 30 & on situation & the-I & underextension \\
\hline
\end{tabular}

Entry 2

\begin{tabular}{|l|l|l|l|}
\hline NP\# & NP & Context for & Type of Error \\
\hline 8 & Japanese culture & the-I & underextension \\
\hline
\end{tabular}

\section{Entry 3}

\begin{tabular}{|l|l|l|l|}
\hline NP\# & NP & Context for & Type of Error \\
\hline 7 & northern area & a/an-I & underextension \\
\hline 9 & second brother & the-I & underextension \\
\hline 18 & soccer ball & $\mathrm{a} / \mathrm{an}-\mathrm{I}$ & underextension \\
\hline 21 & of soccer club & the-I & underextension \\
\hline 23 & not good player & $\mathrm{a} /$ an $-I$ & underextension \\
\hline 31 & in all J apan team & the $-\mathrm{I}$ & underextension \\
\hline 32 & soccer player & $\mathrm{a} / \mathrm{an}-\mathrm{I}$ & uderextension \\
\hline 38 & "advisible" person & $\mathrm{a} / \mathrm{an}-\mathrm{I}$ & underextension \\
\hline 50 & cheerleader & the-I & underextension \\
\hline 55 & job & $\mathrm{a} / \mathrm{an}-\mathrm{I}$ & underextension \\
\hline 56 & of hobby & $\mathrm{a} / \mathrm{an}-\mathrm{I}$ & underextension \\
\hline
\end{tabular}




\begin{tabular}{|c|c|c|c|}
\hline 60 & license & $a / a n-I$ & underextension \\
\hline 63 & the movie & a/an-I & substitution \\
\hline 64 & exhibition & $i / \mathrm{in} n-I$ & underextension \\
\hline 66 & magnificent hobby & $a / a n-I$ & underextension \\
\hline 75 & intelligent person & $a / a n-I$ & underextension \\
\hline 84 & $\begin{array}{l}\text { the rickshaw } \\
\text { (rickshaws) }\end{array}$ & $\emptyset-I$ & overextension \\
\hline 94 & a part-time & $\emptyset-I$ & overextension \\
\hline 95 & so university & the-I & underextension \\
\hline 96 & the company & $\mathfrak{a} / \mathfrak{a} n-I$ & substitution \\
\hline 99 & with smile & $a / a n-I$ & underextension \\
\hline 102 & the money & $\varnothing-I$ & overextension \\
\hline 103 & in Association & the-I & underextension \\
\hline 107 & to Uni. (university) & the-I & underextension \\
\hline 108 & to Uni. (university) & the-I & underextension \\
\hline 111 & a closest person & the-I & substitution \\
\hline 114 & high school student & $a / a n-I$ & underextension \\
\hline 118 & be ballet dancer & $a / a n-I$ & underextension \\
\hline 120 & the interest & $a / a n-I$ & substitution \\
\hline 122 & be dancer & $a / a n-I$ & underextension \\
\hline 123 & teacher & $a / a n-I$ & underextension \\
\hline 128 & hard time & $a / a n-I$ & underextension \\
\hline 129 & overseas country & $a / a n-I$ & underextension \\
\hline
\end{tabular}

\section{Entry 4}

\begin{tabular}{|l|l|l|l|}
\hline NP\# & NP & Context for & Type of Error \\
\hline 11 & critical question & $a / a n-I$ & underextension \\
\hline
\end{tabular}

\section{Entry 5}

\begin{tabular}{|l|l|l|l|}
\hline NP\# & NP & Context for & Type of Error \\
\hline 7 & with JP club & the-I & Underextension \\
\hline 18 & see museum & $a / a n-I$ & Underextension \\
\hline 20 & $\begin{array}{l}\text { eat Japanese } \\
\text { restaurant }\end{array}$ & a/an-I & Underextension \\
\hline 21 & $\begin{array}{l}\text { was public } \\
\text { restaurant }\end{array}$ & a/an-I & Underextension \\
\hline 24 & in U.S. & the-I & Underextension \\
\hline 28 & Japanese beer & a/an-I & Underextension \\
\hline 32 & U.S. & the-I & Underextension \\
\hline 33 & culture & the-I & Underextension \\
\hline 34 & people & the-I & Underextension \\
\hline 35 & environment & the-I & Underextension \\
\hline 37 & food & the-I & Underextension \\
\hline 38 & people & the-I & Underextension \\
\hline
\end{tabular}




\begin{tabular}{|l|l|l|l|}
\hline 39 & environment & the-I & Underextension \\
\hline 40 & food & the-I & Underextension \\
\hline 41 & problem & a/an-I & Underextension \\
\hline 44 & countryside & the-I & Underextension \\
\hline 45 & City & a/an $-I$ & Underextension \\
\hline 49 & traffic jam & a/an-I & underextension \\
\hline
\end{tabular}

\section{Entry 6}

\begin{tabular}{|l|l|l|l|}
\hline NP\# & NP & Context for & Tvpe of Error \\
\hline 3 & $\begin{array}{l}\text { own idea (their own } \\
\text { idea) }\end{array}$ & P-I & other \\
\hline 4 & $\begin{array}{l}\text { or way (their own } \\
\text { way) }\end{array}$ & P-I & other \\
\hline 14 & in U.S. & the-I & underextension \\
\hline 21 & two groups & the-I & underextension \\
\hline
\end{tabular}

\section{Entry 7}

\begin{tabular}{|l|l|l|l|}
\hline NP\# & NP & Context for & Type of Error \\
\hline 1 & About New Year & the-I & underextension \\
\hline 6 & the Christmas & $\emptyset-I$ & overextension \\
\hline 9 & minority & a/an-I & underextension \\
\hline 17 & of ancestors & the-I & underestension \\
\hline 20 & "Gate pines" & the-I & underextension \\
\hline 22 & "secrete" rope & the-I & underextension \\
\hline 32 & New Year & the-I & underextension \\
\hline 50 & from gods & the-I & underextension \\
\hline
\end{tabular}

\section{Entry S}

No errors found. 


\section{APPENDIX D}

Distribution of the errors across the NP Types found in the Japanese students journal entries:

A - Errors of Underextension (179 occurrences)

With NP Type 1 - (30 occurrences) - omission of a/an (10 occurrences): omission of the (20 occurrences)

With NP Type $2-(57$ occurrences $)$ - omission of the

With NP Type 3 - (14 occurrences $)$ - omission of a/an

With NP Type $4-(69$ occurrences $)$ - om ission of a/an

With NP Types 5 - (4 occurrences $)$ - om ission of the

With Countability - (5 occurrences) omission of a/an

B - Errors of Substitution (20 occurrences)

With NP Type 2 - (5 occurrences) used $a / a n$ instead of the

With NP Type 3 - (4 occurrences) used the instend of $a / a n$

With NP Type 4 - (11 occurrences) - used the instead of a/ an ( 5 occurrences): other

determiners - used other instead of another (6 occurrences)

C - Errors of Overextension ( 14 occurrences)

With NP Type 1 - (6 occurrences) - used the instead of 0

With NP Type 4 - (6 occurrences) - used an/an instead of 0 ( 1 occurrence): used the instead of $\emptyset$ ( 5 occurrences $)$

With NP Type 5 - (1 occurrences) - used the instead of 0

With Countability - (1 occurrence) - used $a / a n$ instead of $\theta$ 
D- Orher (problems) - ( 15 occurrences)

With Possessives - (9 occurrences) - 9 occurrences categorized as Other:

With Other Determiners - (6 occurrences) included in the Substitution Error Category 